\title{
Ober den Einfluss der einfachen und der sogenannten mehrfachen Bindung der Atome auf das Licht- brechungsvermögen der Körper.
}

Ein Beitrag zur Erforschung der Konstitution der Benzol- und der Naphthalinverbindungen.

$$
\text { Von }
$$

J. W. Brühl.

In einer im vorigen Jahre erschienenen Untersuchung ${ }^{1}$ ) habe ich bereits des hier zu erörternden Gegenstandes gedacht, jedoch nur gelegentlich und summarisch, wie es dem anderweitigen $Z$ wecke jener Abhandlung angemessen war. Die Frage nach dem Einfluss der verschiedenartigen Bindungsweise der Atome auf die Refraktionsverhältnisse der Körper ist aber nicht allein von grundsätzlicher Bedeutung, sondern sie bildet geradezu den wichtigsten Teil chemisch-spektrometrischer Forschung und das Fundament, auf welchem die ganze Lehre von dem Zusammenhang zwischen Lichtbrechungsvermögen und chemischer Konstitution der Stoffe aufgebaut wurde. Es ist daher Pflicht, dieses Fundament nach Maassgabe der wachsenden Erfahrung auf das sorgfältigste zu prüfen und nach Möglichkeit zu befestigen. Dies soll in der vorliegenden Arbeit meine Aufgabe bilden.

Man wird nun finden, dass mit der Behandlung dieses Problems sich zugleich die so oft erörterte Frage nach der Konstitution des Benzols und des Naphthalins von selbst aufdrängt. Dieselbe wird noch immer, ungeachtet der vielseitigsten experimentellen Bearbeitung und theoretischen Diskussion, als nicht erledigt betrachtet. Auf Grund des hier zusammengetragenen reichen und zum grössten Teil neuen Beobachtungsmaterials und der hierdurch gewonnenen neuen Auffassungsweise glaube ich, dass es mir gelungen ist, dieses schwierige Problem zu einem gewissen Abschluss gebracht zu haben.

j) J. W. Brübl, Jiehige Annal., 935, 1 (1886). 


\section{$\S 1$.}

Nachdem ich kürzlich ${ }^{1}$ ) nachgewiesen habe, dass dem bisher benutzten, vermeintlich unendlich grossen Wellenlängen entsprechenden Refraktionswerte $A$ der Cauchyschen Gleichung thatsächlich cine solche Bedeutung gar nicht beiwohnt und ebensowenig irgend eine andere Formel zur Ermittlung dieses dispersionsfreien Brechungsindex brauchbar ist, wird man zur Zeit auf die sehr wünschenswerte Anwendung einer solchen Konstante verzichten müssen und sich damit begnügen, die Refraktionsverhältnisse in Bezug auf einen Strahl des sichtbaren Teils des Spektrums zu studieren. Als solchen benutze ich hinfort, wie auch schon früher, den rothen Strahl $\alpha$ des Wasserstofflichtes, mit der Sonnenlinie $C$ zusammenfallend, dessen sich auch die meisten anderen Forscher bedienen und für welchen, was die Hauptsache ist, die Atomrefraktion der in organischen Verbindungen vorkommendèn Elemente unmittelbar abgeleitet wurde.

Herr J. H. Gladstone hat dagegen seinen zahlreichen Untersuchungen die Somenlinie $A$ zu Grunde gelegt. Bei schwach dispergierenden Substanzen, wie den meisten Körpern der Fettreihe, unterschieden sich nun die Brechungsindices $n$ für die beiden im roten Teil des Spcktrums befindlichen Linien $A$ und $C$ nur wenig, etwa um 2 oder 3 Einheiten in der dritten Dezimale; z. B. ${ }^{2}$ )

Tabelle 1 .

\begin{tabular}{l|cc}
\hline & $n_{d}$ & $n_{c}$ \\
\hline Chloroform & 1.4438 & 1.4466 \\
Caprylalkohol & 1.4230 & 1.4255 \\
Äthylalkohol & 1.3600 & 1.3621 \\
Athyläther & 1.3529 & 1.3534 \\
Wasser & 1.3284 & 1.3307
\end{tabular}

Es ist dann ziemlich gleichgültig, welchen Index man zur Berechnung der Molekularrefraktion nimmt; die resultierenden Werte weichen nur unwesentlich von einander ab und der Fehler, den man bei der Vergleichung der auf $\boldsymbol{A}$ bezogenen, beobachteten Molekularbrechung mit der Summe der für die Linie $C$ geltenden Atomrefraktionen (theoretischer Refraktionswert) begeht, fällt nicht sehr ins Gewicht. Ganz anders ist dies aber bei den ungesättigten und stets weit dispergenteren Substanzen. Die Indices für $A$ und $C$ differieren dann riel mehr, in manchen Fällen sogar schon in der zweiten Dezimale; z. B. ${ }^{3}$ )

1) J. W. Brähl, a. a. O. und cbendas. 236,233 (1886'. z) J. H. Gladstone n. T. P. Dale, Pbil. Transact. 1863 p. 341. 3) Dieselhen, a. a. 0. 
Ûber d. Einfluss d. einfachen u. der sogenannten mehrfachen Bindung etc. 309

Tabelle 2.

\begin{tabular}{l|c|c}
\hline & $n_{\Lambda}$ & $n_{C}$ \\
\hline Schwefelkohlenstoff & 1.6142 & 1.6240 \\
Cassiaōl & 1.5649 & 1.5727 \\
Phenol & $1.537 \bar{\imath}$ & 1.5433 \\
Benzol & 1.4879 & 1.4931
\end{tabular}

Je nach der Höhe des Molekulargewichts können dann die in Bezug auf die Linie $A$ oder $C$ berechneten Molekularrefraktionen schon beträchtlich, um eine oder mehrere Einheiten in den Ganzen, verschieden sein. Unter solchen Umständen ist es jedenfalls wünschenswert, die Molekularbrechung stets auf ein und dieselbe Lichtart zu beziehen, und zwar auf denjenigen Strahl, für welchen die Werte der Atomrefraktion der Elemente bostimmt worden sind, nämlich die Sonnenlinie $C$.

Obwohl nun Giladstone nur in den seltensten Fällen den Brechungsindex für $C$ gemessen hat, sondern in der Regel den für $A, D$ und $H$, so lässt sich doch jener aus diesen Beobachtungen mit einer völlig genügenden Genauigkeit berechnen. Da ich nun sowohl in der vorliegenden als in einer demuächst folgenden Abhandlung von Gladstones Bestimmungen Gebrauch machen werde, so sei zunächst die Methode erwähnt, deren ich mich zur Ableitung des Brechungsindex für $C$ aus seinen Messungen bediene.

Ich habe gezeigt ${ }^{1}$, dass die Cauchysche Dispersionsgleichung, obwohl ihr keine theoretische Bedeutung mehr beigelegt werden darf, doch als empirischer Interpolationsausdruck zur Ableitung unbekannter Brechungsindices im sichtbaren Teil des Spektrums sehr wohl benutzt werden kann. In der That lassen sich die zu interpolierenden Indices selbst bei den dispergentesten Substanzen, wie Zimmtaldehyd, zimmtsaures Äthyl u. s. w., auf mindestens fünf Einheiten der vierten Dezimale genau ermitteln, falls die Konstanten aus dem Strahlungsgebiete $H \alpha$ bis $H \gamma$, oder $C$ bis fast $G \dot{r}$, mit Hilfe der dreigliedrigen Formel abgeleitet werden. Wenn es sich aber darum handelt, einen einzelnen unbekannten Brechungsindex zu errechnen, so wird man dieselbe und sogar eine noch vollkommenere Genauigkeit schon mit der zweikonstantigen Gleichung Cauchys erreichen können, wenn man den betreffenden Index auf einem möglichst eng begrenzten Kurvenstück aufsucht, d. h. die zur Konstantenableitung benutzten Wellenlängen derjenigen des gesuchten Brechungsindex thunlichst nähert. Aus diesem Grunde wird derselbe für den Strahl $C$ weit genauer aus den

1) J. W. Brühl, Liebigs Annal. 235, 92 (1886) u. 236, 256 ff. (1886). 
Beobachtangen für die Linien $A$ und $D$, als aus denen für $A$ und $H$ zu ermitteln scin. Selbst bei so mächtig dispergierenden Substanzen wio Schwofelkohlenstoff und zimmtsaurem Äthyl kann, wie die nachstehenden Zahlen ergeben, der Wert $\boldsymbol{n}_{c}$ mit Hilfe der so bequemen zweigliedrigen Formel Cauchys bis auf zwei oder drei Einheiten der vierten Dezimale sicher festgestellt werden.

Tabelle 3.

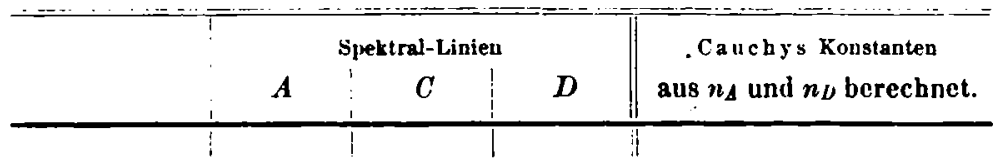

Schwefelkohlenstoff bei $17^{\circ}$ nach v. d. Willigen (LandoltBörnstein, Tabellen, S. 206).

\begin{tabular}{|c|c|c|c|c|}
\hline $\begin{array}{cc}n & \text { beobachtet } \\
n & \text { berechnet } \\
& \text { Differenz }\end{array}$ & $1 \cdot 61136$ & $\begin{array}{l}1 \cdot 62086 \\
1 \cdot 62110 \\
0 \cdot 00024\end{array}$ & $1 \cdot 63034$ & $\begin{aligned} A & ==1.58286 \\
\log . \quad B & =0.21722\end{aligned}$ \\
\hline \multicolumn{5}{|c|}{ Zimmtsaures Äthyl bei $20^{\circ} .6$ nach Wernicke (a. a. 0 ) } \\
\hline $\begin{array}{c}n \text { beobschtet } \\
n \text { berechnet } \\
\text { Differenz }\end{array}$ & $1 \cdot 5451$ & $\begin{array}{l}1.5525 \\
1.5528 \\
0.0003\end{array}$ & 1.5602 & 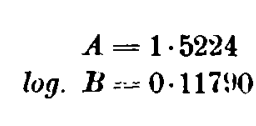 \\
\hline
\end{tabular}

Bei Schwefelkohlenstoff ist ungeachtet der grösseren Dispersion die Ubereinstimmung zwischen beobachtetem und berechnetem $n_{c}$ eine noch etwas bessere, jedenfalls wegen höherer Genauigkeit der Beobachtuıgen.

Der Brechungsindex $u_{c}$ von Körpern geringeren Zerstreuungsvermögens wird daher aus $n_{A}$ und $n_{D}$ mit nahezu absoluter Genauigkeit zu ermitteln sein. Alle die in der Folge angeführten, von Gladstone untersuchten Substanzen besitzen aber eine viel geringere Dispersion als Schwefelkohlenstoff oder zimmtsaures Äthyl.

\section{$\S 2$.}

Nachdem es nun feststeht ${ }^{1}$ ), dass die theoretisch begrüudete Refraktionskonstante

$$
\frac{n^{2}-1}{\left(n^{2}+2\right) \bar{d}}
$$

wie in physikalischer so auch in chemischer Beziehung vor der ïlteren empirischen $\frac{n-1}{d}$ entschieden den Vorzug verdient, werde ich mich nur

1) J. W. Brtihl, Liebigs Annal. 235, 1 (1886) und Ber. d. Deutsch. Chem. Gesellsch. 19, 2746 (1886). 
Ũber d. Einfluss d. einfachen u. d. sogenannten mehrfachen Bindung etc. 311 noch jenes Ausdrucks als Maass des Lichtbrechungsvermögens bedienen. Unter Atom- resp. Molekularrefraktion verstehe ich also immer jene auf den Brechungsindex für die Liuie $C$ bezogene und mit dem Atom- resp. Molekulargewicht $\boldsymbol{p}$ oder $\boldsymbol{P}$ multiplizierte theoretische Konstante.

Als Atomrefraktion der Elemente benutze ich folgende, meiner eben zitierten Abhandlung entnommenen Werte $\left(\frac{n^{2}-1}{n^{2}+2}\right) \frac{p}{d}=r$ :

Tabelle 4.

\begin{tabular}{l|c|c}
\hline \hline & & $r$ \\
\hline Einfach gebundener Kohlenstoff & $C^{\prime}$ & $2 \cdot 48$ \\
Wasserstoff & $I I$ & $1 \cdot 04$ \\
Einfach gebundener Sauerstoff & $O^{\prime}$ & $1 \cdot 58$ \\
Carbonylisch gebundener Sauerstoff & $O^{\prime}$ & $2 \cdot 34$ \\
Chlor & $C l$ & $6 \cdot 02$ \\
Brom & $B r$ & $8 \cdot 95$ \\
Jod & $J$ & $13 \cdot 99$ \\
Einfach gebundener Stickstoff & $V^{\prime}$ & $3 \cdot 192$ \\
Refraktionswert der Äthylenbiudung & $=$ & 1.78 \\
Refraktionswert der Acetylenbindung & $\equiv$ & $2 \cdot 18$
\end{tabular}

$\$ 3$.

Es ist bekanntlich von. J. H. Gladstone ${ }^{1}$ ) im Jahre 1870 darauf aufmerksam gemacht worden, dass die beobachteten Werte der Molekularrefraktion aromatischer Kohlenwasserstoffe stets um eincn annähernd konstanten Betrag grösser sind als diejenigen, welche sich aus den chemischen Forneln der betreffenden Körper mit Hilfe der Landoltschen Atomrefraktionen ${ }^{2}$ ) ergeben. Diese unaufgeklärte Thatsache erhielt eine einfache Deutung durch die im Jahre 1879 von mir $^{3}$ ) gemachte Entdeckung, dass alle ungesättigten Körper, in denen Doppellindungen der Atome angenommen werden, einen derartigen Brechungsüberschuss aufweisen, und dass die Höhe desselben in der Hauptsache von der Zahl der vorhandenen Doppelbindungen abhängt. Man fand bei den Substanzen, welche eine doppelte Bindung der Kohlenstoffatome enthalten, Refraktionsinkremente, die sich einem Durchschnittswerte merklich näherten und von der sonstigen chemischen Beschaffenheit der Körper nicht wesentlich beeinflusst $\mathrm{zu}$ werden schienen. Die Untersuchung einiger zwei Doppelbindungen enthaltenden Körper ergab annähernd zwci Mal so

1) J. H. Gladstone, London Chem. Soc. Journ. 8, 147 (1870). अ) H. Landolt, Pogg. Annal. 123, 595 (1864). $\left.{ }^{3}\right)$ J. W: Brühi, Ber. d. Deutsch. Chem. Gesellsch. 12, 2135 (1879); Liebig's Annal. 200, 139 (1880). 


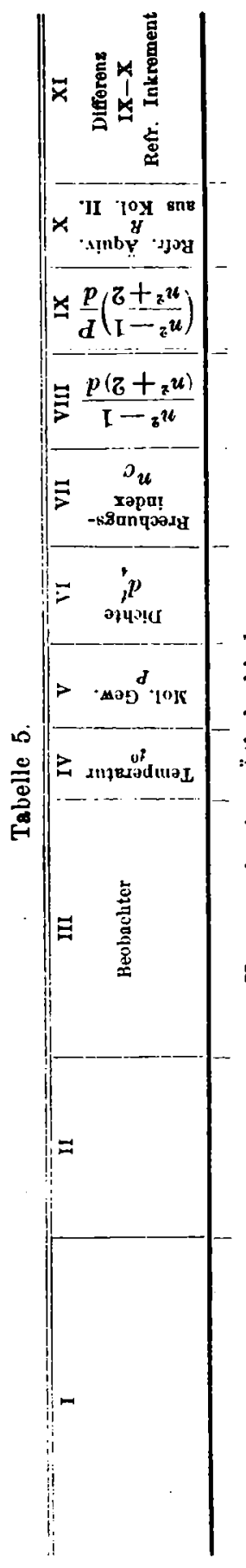

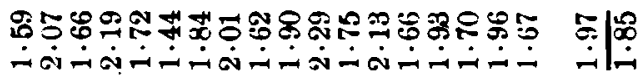

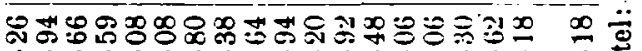

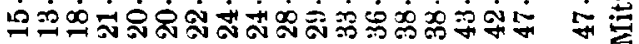

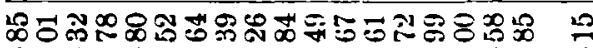

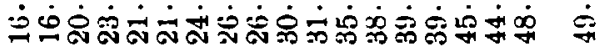

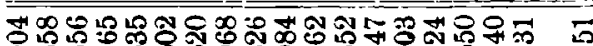

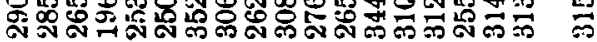

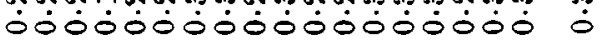

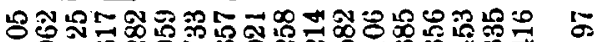

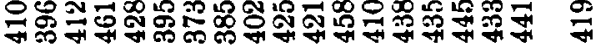

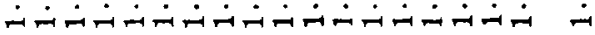

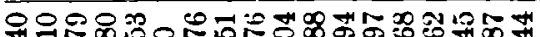

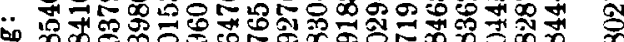
00்㝵

$$
20
$$
L 㱏

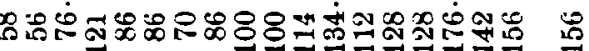

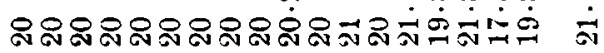

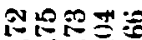
$\because=-\dot{x}=$ $\dot{\sim} \dot{\mathrm{N}} \dot{\mathrm{N}} \dot{\mathrm{N}}$ \|I || if \| i"

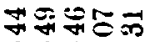

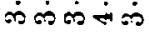

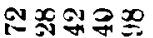

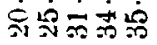
三下舟果

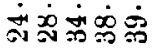

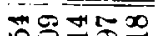
拿品的视 05000 구요요

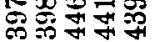

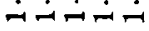

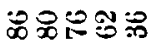

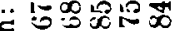
的的安 잉 冚 웅으용

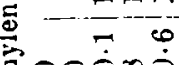
竞
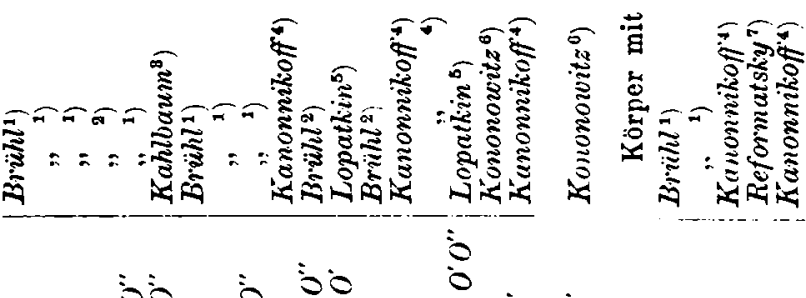
000ี100 09000 00000 is

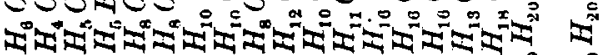

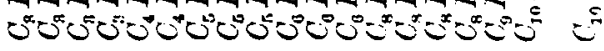
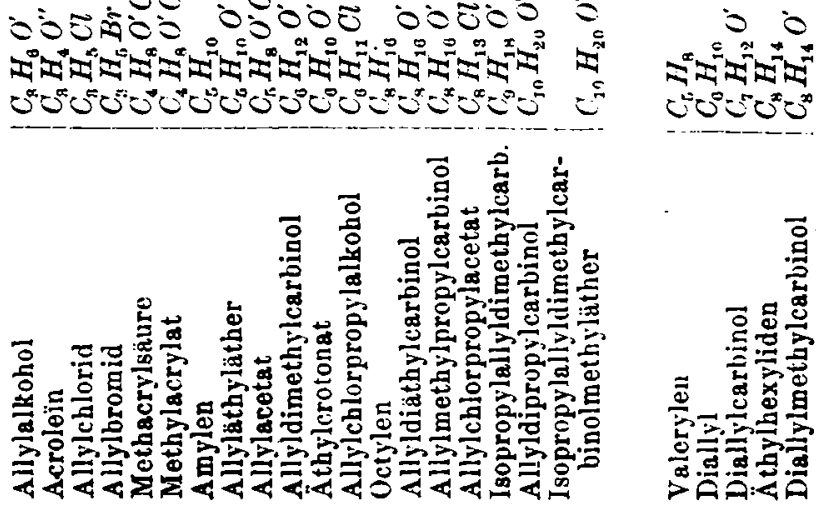
Über d. Einfluss d. einfachen u. d. sogenannten mehrfachen Bindung etc. 313

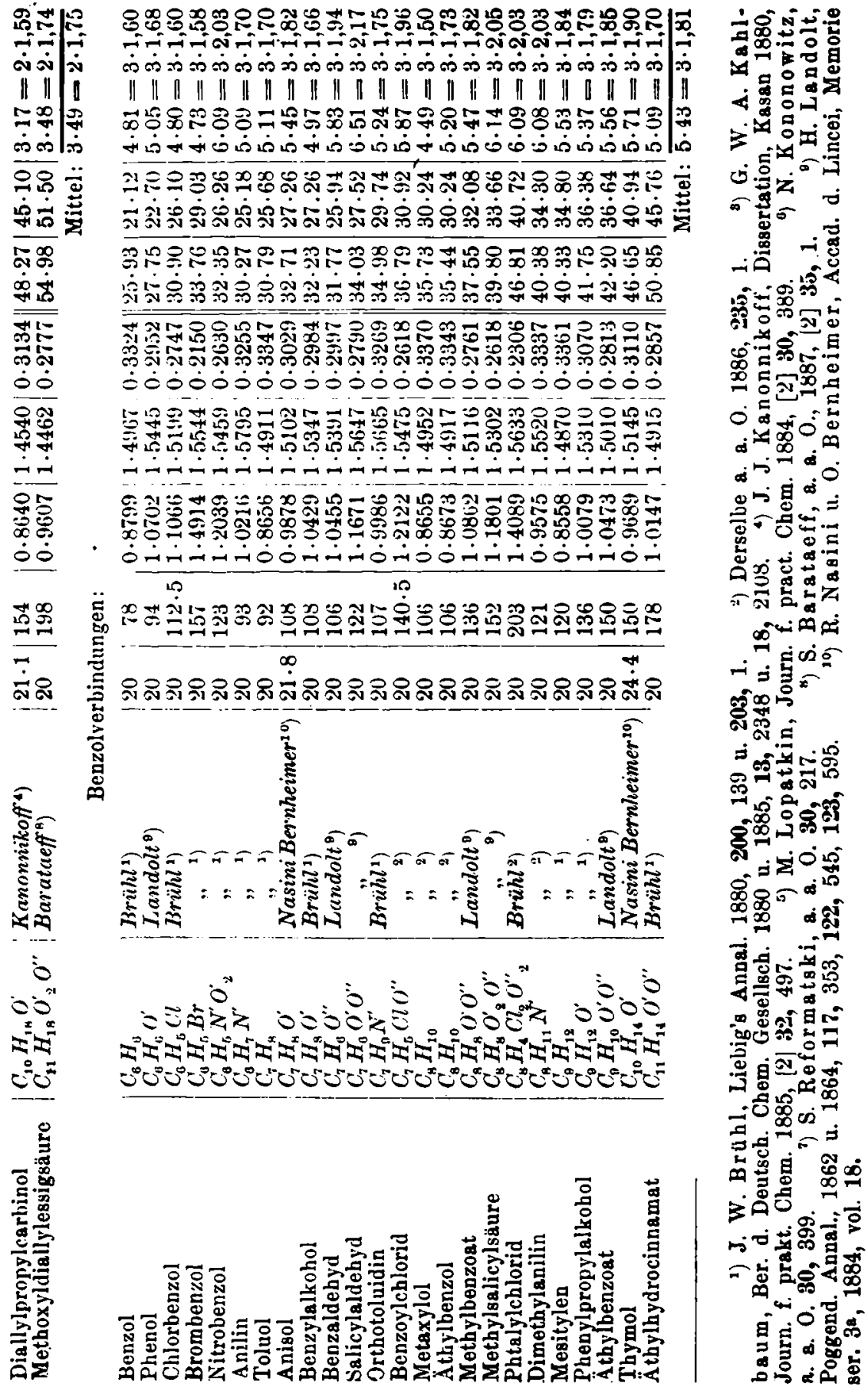


grosse Brechungsüberschüsse, während ungefähr die dreifachen beim Benzol und allen mässig dispergierenden Substitutionsprodukten mit gesättigten Seitenketten beobachtet wurden.

Diese, an einem zunächst ziemlich spärlichen Material aufgedeckten Beziehungen haben seither, sowohl durch die von mir fortgesetzten, als auch durch die Untersuchungen anderer Forscher vielfache Bestätigung gefunden. Die in den verschiedenen Zeitscbriften zerstreuten Beobachtungen habe ich in der vorstehenden Tabelle 5 zusammengestellt, welche übrigens keinen Anspruch auf Vollständigkeit machen soll. So sind z. B. die sehr umfangreichen Messungen von Gladstone, von denen wir zum Teil weiter unten Gebrauch machen werden, in diese Tabelle nicht aufgenommen worden.

Alle hier angeführten Brechungsindices für die Linie $C$ sind direkt beobachtet, nicht interpoliert. Diese Werte, sowie die angegebenen Dichten wurden nun zur Berechnung des auf die neue Refraktionskonstanto bezogenen spezifischen (Kol. VIII) und molekularen Brechungsvermögens (Kol. IX) benutzt. Spalte X enthält das Refraktionsäquivalent der Körper, wie es sich aus der in Kol. II verzeichneten chemischen Formel, also ohne Berücksichtigung der Äthylen- oder sogenannten doppelten Kohlenstoff bindung, als Summe der Atomrefraktionen ergiebt. Im übrigen ist dic Tabelle wohl ohne weiteres verständlich.

Bei der Besprechung der in ihr entbaltenen Resultate können wir uns sehr kurz fassen, da dieselben mit den früheren, aus einer viel beschränkteren Ziahl von Beobachtungen abgeleiteten Èrgebnissen vollständig übereinstimmen.

Man sicht zunächst, dass sämtliche Körper, in denen eine Äthylenbindung angenommen werden darf, Refraktionsiberschüsse orgeben und zwar schwanken die einzelnen Werte zwischen $1 \cdot 44$ und 2.29. Das Mittel aus allen Beobachtungen beträgt 1.85 und die $\Lambda$ bweichung von diesem mittleren Refraktionsinkrement bei den einzelnen Körpern beträgt bald nach der positiven bald nach der negativen Seite ungefähr 0.4 . Bedenkt man nun, dass der von unvollkommener Reinheit der Substanz und aus anderen Ursachen herrührende Versuchsfehler das spezifische Brechungsvermögen $\frac{n^{2}-1}{\left(n^{2}+\overline{2}\right) \dot{d}}$ um circa 0.003 und unter Umständen wohl noch mehr beeinflussen kann ${ }^{1}$ ), die Molekularrefraktion demnach bei einem Molekulargewicht von 100 um 0.3 , bei einem solehen von $200 \mathrm{um} 0.6$ fehlerhaft sein wird, so dürfen die Abweichungen der einzelnen Refraktions-

1) J. W. Brühl, Liebigs Annsl. 235, 37 (1886). 
überschüsse vom mittleren Wert als unwesentliche - innerhalb der unvermeidlichen Ungenauigkeiten liegende - betrachtet werden. Denn diese ganzen Beobachtungsfehler übertragen sich ja unmittelbar auf den kleinen Differenzwert, den Brechungsüberschuss von durchschnittlich 1.85.

Selbst wenn die verschiedenartige Gruppierung der Atome in den vorstehend angeführten Körpern absolut einflusslos auf ihr Lichtbrechungsvermögen wäre - was wohl nicht anzunehmen ist - könnte somit eine grössere Konstanz dieser einzelnen Uberschüsse, in anbetracht der Versuchsfehler, nicht erwartet werden. Wir dürfon daher aus den Thatsachen wohl mit Recht schliessen, dass die mit einer Äthylenbindung ausgestatteten Substanzen ein annähernd konstantes Refraktionsinkrement besitzen, welches in der Hauptsache der Gegenwart eben dieser Bindungsart entspringt. Möglich, ja sogar wahrscheinlich ist es - und ich hobe dies hier geflissentlich hervor - dass die Abweichungen der einzelnen Refraktionsüberschüsse vom mittleren Wert nicht den Versuchsfehlern allein zuzuschreiben sind, sondern dass auch die verschiedene Gruppierung der Atome modifizierend einwirkt, so dass Körper mit einer Äthylenbindung auch aus diesem Grunde niemals eine genaue, sondern immer nur ein annähernd übereinstimmendes Refraktionsinkrement zeigen werden.

Dass indessen der Brechungsüberschuss jener ungesättigten Substanzen im wesentlichen auf die Anwesenheit der Äthylengruppe zurïckzuführen ist, wird durch die zweite Abteilung unserer Tabelle, in welcher zwei Äthylengruppen enthaltende Verbindungen angeführt sind, auf das schönste bestätigt. Die unter einander nicht mehr als vorher abweichenden Refraktionsinkremente erreichen in allen Fällen annähernd den doppelten Betrag desjenigen, welchen die mit einer Äthylenbindung begabten Körper aufweisen, nämlicb in Mittel 2.1,75, wälrend wir 1:85 vorher gefunden hatten. Gerade von dieser Art von Körpern mit zwei Äthylenbindungen werden wir weiter unten noch eine beträchtliche Anzahl anführen und finden, dass sie allemal ein ganz analoges Verhalten zeigen.

Als Generalmittel für das einer Äthylenbindung entsprechende Refraktionsinkrement ergiebt sich also aus den in Tabelle 5 mitgeteilten Beobachtungen an Substanzen, welche eine und zwei Äthylengruppen enthalten, der Wert 1.80. Aus erheblich beschränkterem Material war früher die praktisch identische Zahl 1.78 abgeleitet worden, welche ich, um Verwirrungen zu vermeiden, auch hinfort als Refraktionsäquivalent $r=$ der Äthylenbindung in der Rechnung beibehalten werde.

Die dritte Abteilung der Tabelle umfasst die Beobachtungen am Benzol und 23 Substitutionsprodukten desselben, entstanden durch Ersetzung eines oder mebrerer seiner Wasserstoffatome durch einwertige Atome, an- 
organische Radikale ( $\mathrm{OH}, \mathrm{NO}_{2}, \mathrm{NH}_{\mathrm{z}}$ etc.), oder paraffinische (Fettsäurereihen) Reste. Alle diese Verbindungen besitzen ein bedeutendes Refraktionsinkrement, welches im Mittel 5.43 beträgt. Die Abweichung der einzelnen Werte von dem durchschnittlichen sind, absolut genommen, bei dieser Reihe von Körpern etwas grösser als in den vorhergehenden. Sie erreichen im negativen Sinne den Betrag von 0.7 (beim Brombenzol mit dem Inkrement 4.73) und von 1.1 nach der entgegengesetzten Seite (bei Salicylaldehyd mit 6.51). Berücksichtigt man aber, dass das mittlere Refraktionsinkrement 5.43 drei Mal grösser ist als dasjenige der Äthylenabkömmlinge, 1.81, und ungefähr anderthalb Mal so gross als bei den Diäthylenderivaten, 3.49 , so ergiebt sich, dass die relativen (prozentischen) Abweichungen der einzelnen Brechungsüberschüsse vom mittleren in der Benzolreihe nicht erheblicher sind als in den anderen Reihen. Aus dem absoluten Betrage dieser Abweichungen geht indessen hier deutlich hervor, was vorher nur vermutet, aber nicht aus den Beobachtungen mit Sicherheit konstatiert werden konnte, dass nämlich die Versuchsfehler allein diese Schwankungen des Refraktionsinkrements nicht veranlassen können, sondern dass noch andere Einflüsse vorhanden sein müssen. Unter diesen wird wohl die Wirkung der verschiedenen elementaren Zusammensetzung und Atomkonfiguration eine Rolle spielen. Ferner kommt hier aber noch eine weitere Komplikation hinzu, das ist der Eintluss der grossen und bei den Benzolverbindungen in viel höherem Maasse als bei den Gliedern der Paraffin- und Olefinreihen veränderlichen Dispersion. Dass hierdurch der Brechungsindex, somit auch die Molekularbrechung und das Refraktionsinkrement in ungleicher Weise beeinflusst werden muss, babo ich kürzlich ${ }^{1}$ ) eingehend auseinander gesetzt und brauche demnach hier nicht weiter darauf zurückzukommen.

Ungeachtet aller dieser Einflüsse zeigt sich aber unverkennbar, dass die vorstehend angefïhrten Benzolkörper ein Refraktionsinkrement besitzen, welches dem dreifachen Werte einer Äthylenbindung nahe, in der weitaus überwiegenden Mehrzahl der Fälle sogar sehr nahe kommt.

\section{$\S 4$.}

Die hier geschilderten optischen Beziehungen der Benzolkörper finden wohl die einfachste und wie mir scheint sich von selbst ergebende Erklärung, wenn man annimmt, dass in diesen Substanzen drei Äthylenbindungen vorbanden sind, welche eben die Molekularbrecbung um durch-

1) J. W. BrūhI, Ber. d. Deutsch. Chem. Gesellsch. 19, 2746 (1886); auch in den schon zitierten Abhandlungen in Liebigs Annalen. 
schnittlich 3·1,80 anwachsen lassen. Ich habe denn auch seiner Zeit, als die Beziehungen $z$ wischen der Molekularbrechung und der chemischen Beschaffenheit der ungesättigten Körper von mir aufgefunden wurden, nicht gezögert, jenen Schluss zu ziehen und das optische Verhalten der Benzolverbindungen als ein gewichtiges Argument zu Gunsten von Kekulés Konstitutionsformel zu erklären.

Nimmt man diese Interpretation für die spektrometrischen Verhältnisse der aromatischen Substanzen als richtig an, so folgt aus derselben unmittelbar, dass einfache, ringschliessende Bindungen auf dic Molekularrefraktion einflusslos sind, weder einen Zuwachs noch eine Abnahme bewirken. Denn im Benzol und seinen Abkömmlingen sind ja nach Kekulés Formel neben drei Äthylen- drei einfache, ringbildende Verkettungen vorhanden. Wenn nur die ersteren den Refraktionszuwachs bewirken, so sind die letzteren offenbar in optischer Beziehung von keinem besonderen Finfluss. Iie praktische Bedeutung dieser weiteren Schlussfolgerung liegt auf der Hand. Denn falls die Annahme der Wirklichkeit entspricht, müsste es möglich sein, vermittelst der Molekularbrechung festzustellen, ob in einem Körper $\left(C_{n} H_{2}{ }_{n+2}\right)-x H_{2}$ Äthylengruppen, und wic viele derselben vorhanden sind.

Allein es lässt sich nicht in Abrede stellen, dass die von mir gegebene Deutung des optischen Verhaltens der Benzolverbindungen nicht die cinzig mögliche ist, obwohl sie entschieden als die ungezwungenste erscheint und deshalb auch ursprünglich allein zur Diskussion gebracht wurde.

Nimmt man nämlich an, dass der Benzolkern nicht durch drei doppelte und drei einfache, sondern durch neun einfache Bindungen zusammengehalten sei, so wäre es nicht ausgeschlossen, dass auch dann ein Refraktionsüberschuss entsteht, der demjenigen gleich kommt, welchen eine Molekel $C_{6} H_{6}$ von der Kekuléschen Konstitutionsformel bewirken würde. Dies köunte dann der Fall sein, wenn zwei einfache einer doppelten Kohlenstoff bindung optisch äquivalent wären. Denn die beiden in Frage kommenden Konstitutionsschemata unterscheiden sich ja eben darin, dass in dem einen statt dreier doppelten sechs einfache Bindungen vorkommen.

Das zu lösende Problem besteht also darin, zu konstatieren, ob die einfache Kohlenstoffverkettung überhaupt einen besonderen Einfluss auf die Molekularrefraktion ausübt und ob zwei solcher einfachen Bindungen in optischer Beziehung einer doppelten gleichwertig sind. Diese Frage ist einer experimentellen Behandlung zugänglich und wir werden nun versuchen, sie an der Hand der Erfahrung zu entscheiden.

Die Atomrefraktion des einfach verketteten Kohlenstoffatoms, $r C^{\prime}$, wurde zu 2.48 festgestellt. Wie kam man zu diesem Werte? Es wurde 
zunächst das Refraktionsäquivalent der Gruppe $\mathrm{CH}_{2}$ aus den homologen Reihen paraffinischer Abkömmlinge, z. B. aus den Alkoholen, Säuren, Aldehyden u. 8. w., abgeleitet. Dann wurde der optische Werth von $H_{q}$ ermittelt, indem man von der Molekularbrechung der Verbindungen $C_{n} H_{2 n+2}=n C_{2}+H_{2}$ oder derjenigen ihrer Derivate den Wert von ${ }_{n} \mathrm{CH}_{2}$ abzog. Endlich ergab sich die Atomrefraktion des Kohlenstoffes selbst durch Subtraktion des optischen Äquivalents von $H_{2}$ von demjenigen der Gruppe $\mathrm{CH}_{\mathbf{2}} \cdot{ }^{\text {) }}$ )

Die so erhaltene Konstante $r C^{\prime}=2.48$ bezieht sich also auf ein in paraffinischen Verbindungen enthaltenes, d. h. mit anderen Kohlenstoffatomen einfach verkettetes Kohlenstoffatom. Wenn dieser einfachen Bindungsform überhaupt ein eigenes Refraktionsäquivalent zukommt, so ist dasselbe offenbar in dem Werth $r C=2.48$ schon mit eingeschlossen. Das Vorhandensein eines der einfachen Kohlenstoffverkettung zukommenden Einflusses auf die Atomrefraktion dieses Elements wird sich nun zeigen müssen, wenn man die Molekularrefraktion solcher organischen Verbindungen, welche nur ein Atom Kohlenstoff enthalter, cder mehrere, aber nicht unmittelbar miteinander verkettete, untersucht. Die Vergleichung der beobachteten Molekularbrechung mit der aus der chemischen Formel sich ergebenden Summe $R$ der Atomrefraktionen, in welche Summe für den Kohlenstoff der Wert $r C^{\prime}=\mathbf{2 . 4 8}$ eingefürt wurde, muss diesen Einfluss zu Tage treten lassen. Eine diesbezügliche Zusammenstellung findet man in der folgenden Tabelle.

Tabelle 6.

\begin{tabular}{|c|c|c|c|c|c|c|c|}
\hline & & Beoblachter & $d^{31}$ & $n_{t}$ & 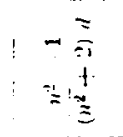 & 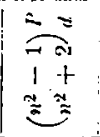 & $n$ \\
\hline Methylalkohol & $\mathrm{CII}_{4} \mathrm{O}^{\prime}$ & Landolt: & 0.7953 & $1 \cdot 3279$ & 0.2550 & $8 \cdot 16$ & 8.22 \\
\hline Methyljodid & $\left(\mathrm{H}_{3} \mathrm{I}\right.$ & $\operatorname{Haagen}^{3}$ ) & $2 \cdot 2582$ & 1.5243 & 0.1356 & $19 \cdot 25$ & $19 \cdot 59$ \\
\hline Ameisensäure & $\mathrm{CHI}_{2} \mathrm{O}^{\prime} \mathrm{O}^{\prime \prime}$ & $L\left(t n d o l t^{z}\right)$ & $1 \cdot 2188$ & $1 \cdot 3693$ & $0 \cdot 1853$ & $8 \cdot 52 !$ & $8 \cdot 48$ \\
\hline Chloroform & $(\mathrm{HC})$ & Huragen $\left.{ }^{3}\right)$ & 1.1898 & 1.4440 & $0 \cdot 1783$ & $21 \cdot 31$ & 21.58 \\
\hline Kohlenperchlorid & $C\left(l_{4}\right.$ & , 3) & $1 \cdot 5912$ & 1.4579 & 0.1715 & $26 \cdot 40$ & 26.56 \\
\hline Methylal & $\mathrm{CH}_{\mathrm{i}} \mathrm{OO}^{\prime} \mathrm{CH}$ & $\left.B r u ̈ h l^{*}\right)$ & 0.8604 & 1.3518 & 0.2513 & $19 \cdot 10$ & 18.92 \\
\hline
\end{tabular}

1) Das zu diesen Ableitungen benutate Beobachtungsmaterial war gerade kein sehr umfangreiches (man vergl. H. Landolt, Liebigs Ann. 213, 75 [1882]). Ich habe wich inlessen davon überzeugt, dass bei Hinzuziehung aller bisher vorliegenden, mehr als 100 ) Verbindungen umfassenden Beobachtungen kein wesentlicher Unterschicd in den Zahlenwcrten (Atomrefraktionen) resulticrt. lch werde bei einer nächsten Gelegenheit ausführlicher auf diesen Gegenstand zurückzukommen haben. 9) H. Landolt, Pogg. Ann. 117, 353 u. 122, $545(1862-63)$. ') A. Hasgen, a. a. O., 131, 117 (1867). ‘) J. W. Brüh l, Liebigs Ann. 203, 1 (1880). 
Uber d. Einfluss d. einfachen u. d. sogenannten mehrfachen Bindung etc. 319

Die nahezu absolute Ubereinstimmung zwischen der beobachteten Molekularrefraktion und dem berechneten Werte $R$ bei allen vorstehenden Körpern lässt keinen $\mathrm{Zweifel} \mathrm{darüber,} \mathrm{dass} \mathrm{den} \mathrm{in} \mathrm{ihnen} \mathrm{enthaltenen}$ Kohlenstoffatomen derselbe Wert 2.48 entspricht, der auch dem mit anderweitigen Kohlenstoffatomen verbundenem Kohlenstoff zukommt. Die ein fache Verkettung der Kohlenstoffatome untereinander übt also auf die Atomrefraktion dieses Elements und auf die Molekularbrechung seiner Verbindungen keinen gesonderten Einfluss aus. Die Atomrefraktion des gesättigten Kohlenstoffatoms, $r C^{\prime}=2.48$, bleibt dieselbe, ob nun seine vier Affinitäten ganz oder teilweise durch einzelne Kohlenstoffatome oder durch sonstige einwertige Substituenten befriedigt werden.

Es scheint mir bereits hieraus mit Wahrscheinlichkeit hervorzugehen, dass ein Gebilde von der Formel

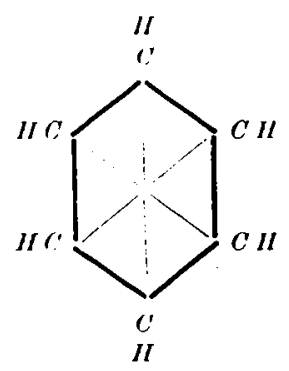

oder von irgend einer anderen Konfiguration mit neun einfachen Kohlenstoffbindungen normale Molekularbrechung - ohne Refraktionsüberschuss - besitzen müsste. Denn sämtliche Kohlenstoffatome eines solchen Körpers befinden sich im Zustande völliger Sättigung, in welchem Falle denselben der konstante Wert $r C^{\prime}=2.48$ zukommt.

Dass in der That auch bei den ringförmig geschlossenen Gebilden der allgemeinen Formel $\left(C_{n} H_{2 n+2}\right)-x \boldsymbol{H}_{2}$ das aus der empirischen $\mathbf{Z u}-$ sammensetzung folgende Refraktionsäquivalent $R$ durch einfache Kohlenstoffbindungen nicht geändert wird, ebensowenig wie es in den offenen paraffinischen Ketten $C_{n} I_{2 n+2}$ geschicht, lässt sich, wie nun nachgewiesen werden sull, ebenfalls durch dis Experiment unmittelbar feststellen.

\section{$\$ 5$.}

Von grossem Interesse sind in dieser Hinsicht die optischen Erscheinungen, welche den Vorgang der Polymerisation begleiten. Da derselbe am genauesten bei den Aldehyden, und speziell bei der Umwandlung von 
Acet- in Paraldehyd studiert ist, so wollen wir zunächst diesen Fall betrachten.

Der Sauerstoff verhält sich, wie ich früher nachgewiesen hale, dem Kohlenstoff prinzipiell analog. In Körpern, in welchen er doppelt gebunden vorkommt, wie in den Aldehyden, Ketonen n. s. w., besitzt er eine beträchtlich höhere Atomrefraktion als in den Alkoholen, Äthern u. s. w. Bestimmt man den optischen Wert des Sauerstoffs aus den nach der Formel $C_{n} H_{2 n} O^{\prime \prime}$ zusammengesetzten Substanzen der ersteren Art, indem man von ihrer Molekularbrechung das Refraktionsäquivalent $C_{n} H_{2}=n C H_{2}$ abzieht, so erhält man als Atomrefraktion des zweifach an Kohlenstoff gebundenen Sauerstoffs $r O^{\prime \prime}=2.34$. Wird dagegen von der Molekularbrechung der Säuren oder Ester $C_{n} H_{2 n} O^{\prime \prime} O^{\prime}$ diejenige der Aldehyde oder Ketone $C_{n} H_{2 n} O^{\prime \prime}$ abgezogen, so ergieht sich der Wert des Hydroxyl- und des Alkyloxylsauerstoffs, $c_{-} O_{-}$und $c_{-} O_{-} c_{\text {. }}$ Dieses einfach verkettete Sauersoffatom besitzt in beiden Gruppen fast vollständig identischon Refraktionswert, welcher im Mittel zu $r O^{\prime}=1.58$ gefunden wird und auch bei den Alkobolen und Äthern nahezu gleich ist.

Der Doppelbindung zwischen Sauerstoff und Kohlenstoff kommt demnach ein Brechungsinkrement zu, welches den Betrag von 2.34-1.58 $=0.76$ erreicht.

Der Vorgang bei Polymerisation von Acet- und Paraldehyd beruht nun nach der heute wohl allgemeinen Annahme in der Umwandlung von drei doppelten in sechs einfache Bindungen, welchen Prozess man durch die Formeln

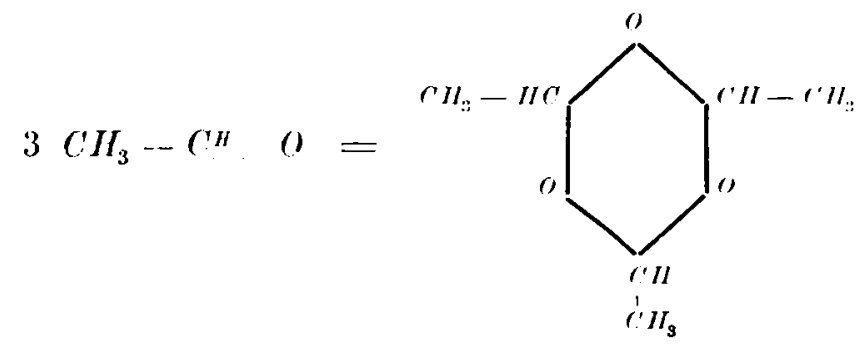

darstellen kann, dessen Analogon der bisher noch nicht effektuierte Ubergang von Äthylen in Hexahydrobenzol sein würde.

Wenn nun drei doppelte sechs einfachen Bindungen optisch äquivalent wären, so nüusste die Molekularrefraktion des Paraldehyuds drei Mal so gross sein als diejenige des Acetaldehyds, oder das Brechungsvermögen gleicher Gewichtsmengen dieser Körper müsste gleich sein. Die Beohachtung ergiebt nun folgendes: 
Über d. Einfluss d. einfachen a. d. sogenannten mehrfachen Bindung etc. 321

Tabelle 7.

\begin{tabular}{ll|l|l|l|l|l}
\hline & & Beobachter & $d^{0}$ & $n_{c}$ & $\frac{n^{2}-1}{\left(n^{2}+2\right) d}$ & $\left(\frac{n^{2}-1}{n^{2}+2}\right) \frac{P}{d}$ \\
\hline Acetaldehyd & $C_{z} H_{4} O$ & Landolt & 0.7799 & 1.3298 & 0.2615 & 11.50 \\
Paraldehyd & $C_{6} H_{1 z} O_{3}$ & Briihl & 0.9943 & 1.4030 & 0.2454 & 32.40
\end{tabular}

Die in der vorletzten Spalte enthaltene spezifische, das ist die mit dem Molekulargewicht $\boldsymbol{P}$ der Körper dividierte Molekularrefraktion, ist identisch mit dem Brechungsvermögen gleicher Gewichtsmengen. Wie man nun sicht, findet eine Übereinstimmung dieser Konstante bei den beiden Verbindungen nicht statt, sondern es erfolgt bei der Polymerisation eine bedeutende Abnahme des spezifischen Brechungsvermögens. Vergleicht man aber die Molekularrefraktion, so ergiebt sich, dass diejenige des Paraldehyds nicht drei Mal so gross ist wie die des Acetaldehyds, $3 \cdot 11,50=34 \cdot 50$, sondern um $34 \cdot 50-32 \cdot 40=2 \cdot 10$ kleiner.

Wie nun vorher erwähnt wurde, beträgt das Brechungsäquivalent der Doppelbindung zwischen Sauerstoff und Kohlenstoff 0.76. Falls die Verminderung des Brechungsvermögens bei dem vorliegenden Polymerisationsvorgang auf dem Verschwinden dreier Doppelbindungen beruhen würde, sollte also diese Verminderung $3 \cdot 0,76=2.28$ ausmachen. In der That erreicht sie den Wert 2.10 und die Ubereinstimmung zwischen dem erwarteten und dem beobachteten Betrag ist also eine so vorzügliche, dass über den Einfluss der Doppelbindung auf die Erhöhung der Molekularrefraktion kein Zweifel bestehen kann; und ebensowenig darüber, dass die sechs einfachen Sauerstoff- Kohlenstoff-Bindungen im Paraldehyd drei doppelten Bindungen dieser Elemente weder optisch gleichwertig sind, noch überhaupt irgend welche Refraktionszunahme bewirken.

$\S 6$.

Die Erscheinung der Polymerisation lässt sich auch an den Kohlenwasserstoffen spektrometrisch verfolgen, und $\mathrm{um}$ so einladender ist eine diesbezügliche Untersuchung, als hier neben der Polymerie zugleich auch eigentliche Isomerie stattfinden und in ihren optischen Wirkungen beobachtet werden kann.

Mit dem Amylen, $C_{5} H_{10}=$, welches, wie die nebenstehende Formel ausdrückt, eine Äthylenbindung enthält, ist das Diamylen polymer. Dasselbe gehört (und mit ihm wie es scheint alle bisher bekannten olefinischen Polymerisationsprodukte) selbst noch zur Klasse der Olefine. ${ }^{1}$ ) Es

1) Man vergl. A. But,le row, über Isodibutvlen, Liebigs Ann. 189, 44 (1877). 
vereinigt sich nach Bauer ${ }^{1}$ ) mit den Halogenen aufs begierigste zu Verbindungen von der Formel $C_{10} H_{80} X_{2}$. Im Diamylen ist demnach noch eine Äthylengruppe vorhanden, seine Zusammensetzung ist $C_{10} H_{20}=$. Mit Diamylen isomer sind zwei andere Körper, nämlich das nach Baeyer ${ }^{8}$ ) aus Terpentinöl mit Jodphosphonium gewonnene Tetrahydroterpen, und das Cymhydren, welches nach Armstrong ${ }^{9}$ ) durch Einwirkung von Jod auf Kampher und noch auf andere Weise erhalten werden kann. $\mathrm{Ob}$ diese beiden Substanzen mit einander identisch oder isomer sind, ist noch nicht sicher festgestellt. Sie verhalten sich indessen beide als gesättigte Körper, sind gegen Halogene, conc. Schwefelsäure u. s. w. ganz indifferent und müssen demnach als ringförmige Gebilde, ohne Äthylenbindung, angesehen werden. Für das Tetrahydroterpen (und vielleicht auch das Cymhydren) darf wohl in anbetracht der nahen Beziehungen der Terpene (und des Kamphers) zum Cymol die Konstitution

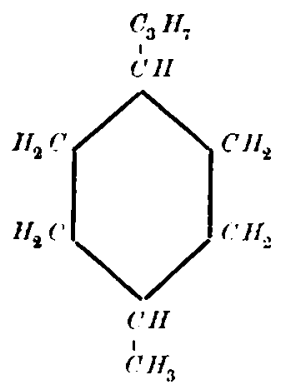

als wahrscheinlich bezeichnet werden. Von dem isomeren Diamylen ist die atomistische Struktur nicht bekannt, nur so riel steht, wic gesagt, fest, dass es ein ungesättigtes, olefinisches und kein ringförmiges Gebilde ist. Mit den beiden vorgenannten Körpern ist es demnach süttigungsisomer, während diese unter sich, wenn nicht identisch, nur stellungsisomer sein können. Die Beziehungen der erwähnten Substanzen sind in folgender Zusammenstellung ausgedrückt:

$\begin{array}{ll}\text { Amylen } & C_{5} H_{10}= \\ \text { Diamylen } & C_{10} H_{20}= \\ \text { Tetrahydroterpen } & C_{10} H_{20} \\ \text { Cymhydren } & C_{10} I I_{80}\end{array}$

In dem gleichen Verbältnisse wie Amylen zum Diamylen steht das

1) A. Bau er, Sitzungsber. Wien. Akad. 2. Abt. 44, 87 (1862); Zeitschr. Chem. 1861 S. $645 . \quad$ 9) Ad. Baeyer, Liebigs Annal. 155, $276(1870$ ). 3 ) H. E. Armstrong a. Easkell, Ber. Deutsch. Chem. Gesell., 11, 151 (1878); Armstrong, a. a. $0 ., 12,1755$ u. 1759 (1879): Armstrong u. A. K. Miller, a. a 0. 16, 2255 (1883). 
Ober d. Einfluss d. einfachen u. d. sogenannten mehrfachen Bindang etc. 323

Penten, $C_{5} H_{8}==_{2}$ (aus Terpentinöl durch hohe Temperatur')) und das Isopren $C_{5} H_{8}=$ (durch Destillation von Kautschuk 2)) zum Diisopren $\mathrm{C}_{10} \mathrm{H}_{1 \mathrm{6}}=2$. Die komplexere Verbindung ist das Polymerisationsprodukt der einfacberen, aus welcher sie entstanden ist, indem sich zwei Molekel unter Aufhebung der Hälfte der vorhandenen Äthylenbindungen kondensierten. Das Penten und das Isopren vereinigen sich mit Leichtigkeit mit zwei Molekeln Halogen oder Halogenwasserstoff und das gleiche thut auch das Diisopren ${ }^{3}$ ), so dass in allen diesen Körpern zwei Äthylenbindungen anzunehmen sind.

Ob Penten und Isopren, wie Tilden annimmt, identisch sind oder isomer, steht noch nicht fest, so viel ist jedoch sicher, und darauf kommt es hier allein an, dass die beiden Substanzen nicht sättigungs-, sondern höchstens stellungsisomer sein können. Ihre Zusammensetzung wird durch die gemeinschaftliche Formel $\left.C_{5} H_{8}\right|_{2}$ ausgedrückt. ${ }^{4}$ )

Wie Penten und lsopren zum Valerylen, so steht das Diisopren zum Limonen (im Limonen- und Orangenöl vorkommend). Beide um $180^{\circ}$ siedenden Terpene sind ebenfalls stellungsisomer. Sie vereinigen sich mit gleicher Leichtigkeit mit zwei Molekeln Halogen oder Halogenwasserstoff ${ }^{5}$ ) zu isomeren Verbindungen der Formel $\mathrm{C}_{10} \mathrm{H}_{16} .2 \mathrm{HCl}, \mathrm{C}_{10} \mathrm{H}_{16} .2 \mathrm{Br}_{2}$ u. s. w.; ihre Zusammensetzung entspricht der gemeinschaftlichen Formel $C_{10} H_{16}:==_{2}$. Für das Limonen ist kürzlich ${ }^{6}$ ) die Konstitution

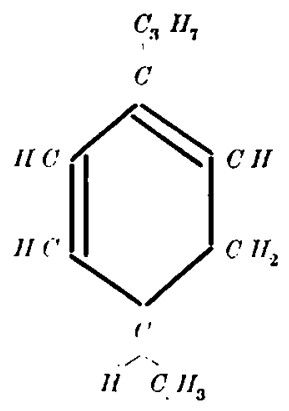

1) Tilden, Chem. Soc. Journ. t5, 410 (1884). 2) Greville-Williams, Lond. Roy. Soc. Proceed. 10, 516 (1860); Bouchardat, Compt. rend. 80, 1446 (1875), 89, 361 (1879). 3) W allach, Liebigs Annal. 297, 292 (1885). 4) Wabrend Tilden geneigt war, diesen Körpern die Konstitution $\mathrm{CH}_{3}-\mathrm{CH}=\mathrm{C}=\mathrm{CH}-\mathrm{CH}_{3}$ zuzuschreiben, ist nach neueren Untersuchungen (Gadziatzky, Bull. soc. chim. 47, 168 [1887]) für Isopren die Formel $\mathrm{H}_{3} \mathrm{C}>\mathrm{C}-\mathrm{CH}=\mathrm{CH}_{2}$ wahrscheinlich gemacht worden. 5) O. Wallach, Liebigs Annal. 225, $291 \mathrm{ff.},(1884), 227,277$, 230, 225 (1885). $\quad$ : II e in rich Goldschmidt, Ber. Deutsch. Chem. Gesell., 20, 491 (1887). 
festgestellt worden; diejenige des anderen Terpenes, des Diisoprens, ist noch nicht bekannt; sie könnte etwa durch die Formeln
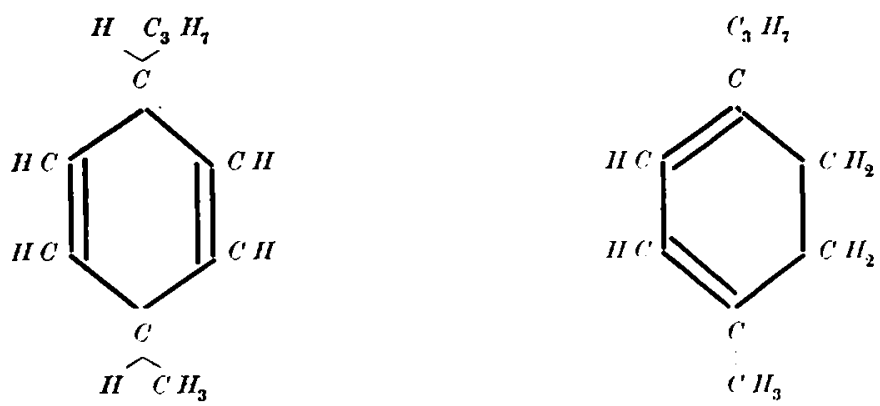

oder ähnliche Schemata ausgedrückt werden.

Eine andere Klasse vou Terpenen, die mit den vorigen nicht stellungs-, sondern sättigungsisomer sind, bilden die um $160^{\circ}$ siedenden Kohlenwasserstoffe des Terpentinöls und anderer ätherischer Öle. Diese, unter den Sammelnamen „Pinene“ (wegen des allgemeinen Vorkommens in den ölen der Pinusarten) zusammengefassten Substanzen vereinigen sich nur mit einer Molckel Halogen oder Halogenwasserstoff, ihre gemeinsame Formel ist $C_{10} H_{16}=$. Dem Pinen wird die Konstitution

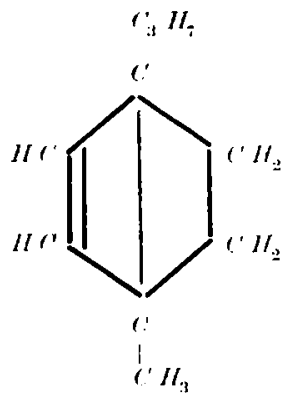

zugeschrieben. Es ist klar, dass auch hier, je nach der Verteilung der Wasserstoffatome und der gegenseitigen Stellung der Äthylen- und der Parabindung, zahlreiche Stellungsisomere vorkommen können.

Die erwähnten Hemiterpene $C_{5} H_{8}$ und Terpene $C_{10} I I_{16}$ stehen also zu einander in dem durch folgende Formeln bezeichneten Verhïltnisse:

\begin{tabular}{l|l}
$\begin{array}{l}\text { Penten } \\
\text { Isopren } \\
\text { Diisopren }\end{array}$ & $C_{5} H_{8}=2$ \\
Limonen & $C_{10} H_{16}=2$ \\
Pinen & $C_{10} H_{16}=$
\end{tabular}


Ober d. Einfluss d. einfachen u. d. sogenannten mehrfachen Bindung etc. 325

Entsprechende Fälle von Saturations- und Positionsisomerie lassen sich auch für eine Anzahl sauerstoff haltender Körper spektrometrisch verfolgen.

Das Allyldipropylcarbinol ${ }^{1}$ ) und der Isopropyl-DimethylkarbinolMethyläther ${ }^{2}$ ) sind stellungsisomer. Sie besitzen die gemeinsame Formel $C_{10} H_{20} O^{\prime}=$ und die Konstitution dieser Körper ist durch die Synthese, wie durch den analytischen Abbau festgestellt:

$$
\begin{gathered}
\mathrm{CH}_{2}=\mathrm{CH}-\mathrm{CH}-\mathrm{C}\left(\mathrm{C}_{3} \mathrm{H}_{7}\right)_{2} \cdot \mathrm{OH} \\
\text { Allyldipropylkarbinol } \\
\left(\mathrm{CH}_{3}\right)_{2} \mathrm{CH}-\mathrm{CH}=\mathrm{CH}-\mathrm{CH}-\mathrm{C}_{2}\left(\mathrm{C}^{\prime} \mathrm{H}_{3}\right)_{2} \cdot \mathrm{O} \mathrm{OCH} \mathrm{H}_{3}
\end{gathered}
$$

Isupropylallyl-Dimethylkarbinol-Methyläther

Sättigungsisomer mit denselben ist der Menthakampher oder Menthol, $C_{10} H_{20} O^{\prime}$, ein gegen Halogene u.s. w. indifferenter Alkohol, welcher also keine Äthylengruppe enthält, und dem wegen seiner nahen Beziehungen zu den übrigen Kampherarten und dem Cymol die Konstitutionsformel

zugeschrieben werden darf.

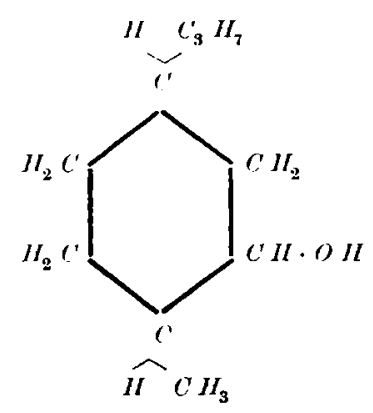

Sättigungsisomer sind ferner drei Körper von der empirischen Formel $C_{10} H_{18} O$ : das von Kanonnik off $\left.{ }^{3}\right)$ dargestellte Diallylpropylkarbinol

$$
\left(C H_{2}=C H-C H\right)_{2}\left(C_{3} H_{7}\right) C . O H,
$$

das Terpineol (aus dem Terpinhydrat $C_{10} H_{18}(O H)_{2}+H_{z} O$ und dem Terpenchlorid $C_{10} H_{18} C l_{z}$ ) und das Cineol. Das Terpineol ist nach Wallachs ${ }^{4}$ ) Untersuchungen ein ungesättigter Alkohol mit einer Doppelbindung. Das Cineol und das damit identische Cajeputol (aus dem ätherischen Öl von Artemisii Cynae und demjenigen mehrerer Melaleuca-Arten) bildet dagegen nach demselben Forscher ${ }^{5}$ ) eine gesättigte Verbindung, in welcher der Saucrstoff zwei Kohlenstoffatome verkettet, wie etwa im

1) J. J. Kan onnik off, Journ. pract. Chem. [2], 32, 497 (1885).

2) W. Dieff u. N. Kononowitz, a. a. 0., 27, 364 u. 30, $399(1883-84)$.

3) Kanonnik off, a. a. O. †. Wallach, Liebigs Annal. 230, 254 (1885).

s) Derselbe, a. a. 0., 225, 291 (1884). 
Äthylenoxyd. Die Konstitution dieser Substanzen könnte z. B. dargestellt werden durch die Schemata:
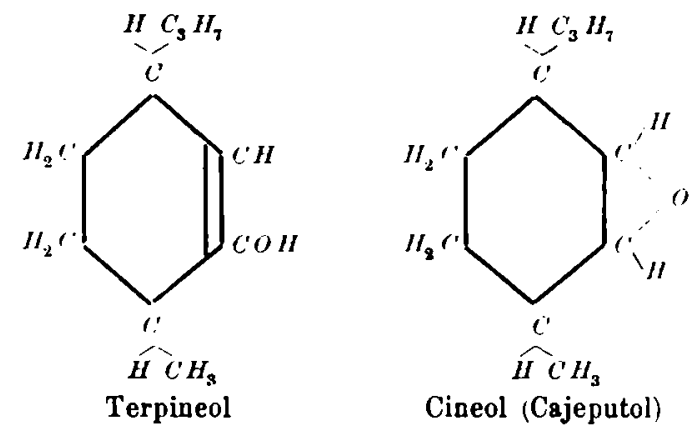

welche hier nur ein Bild von den Sättigungsverhältnissen geben, keineswegs aber dic noch unbekanute gegenseitige Stellung der Atome ausdrücken sollen.

Die hier erwähnten Relationen der genaunten sauerstoffhaltigen Körper lassen sich also auch bezeichnen mit den Formeln:

Allyldipropylkarbinol

Isopropy]allyl-Dimethylkarbinol-Methyläther

Menthol

$\left(_{10}^{1} H_{20} O^{\prime}=\right.$

Diallylpropylkarbinol

$U_{10} I_{2 n} O^{\prime}$

Terpineol

$C_{10} I_{18}()^{\prime}=$

Cineol

$C_{10} H_{18} O^{\prime}=$

$C_{10}^{\prime} H_{18}()^{\prime}$

wobei noch bemerkt werden mag, dass das Sauerstoffatom im Cineol mit $O^{\prime}$ ausgedrückt ist, weil es wie im Hydroxyl, dem Alkyloxyl $C_{-\ldots} O-C$ der Äther u. s. w. einfach gebunden ist, im Gegensatz zum Carbonylsauerstoff $O^{\prime \prime}$ der Aldehyde, Ketone u.s. w.

\section{$\$ 7$.}

Nachdem das zum Verstäudnis des Nachfolgenden Erforderliche betreffs des chemischen Charakters, insbesondere des Sättigungszustandes der Polymeren und Isomeren, welcher hier allein (nicht aber die nähere Atomkonfiguration) in Betracht kommt, vorangeschickt worden ist, wenden wir uns nun zur Betrachtung des physikalischen Verhaltens der erwähnten Körper.

Für sie alle sind Dichte und Brechungsindices bekannt und ich stello dieselben, nebst dem ron mir aus diesen Daten berechneten spezifischen Brechungsvermögen $\frac{n^{2}-1}{\left(n^{2}+2\right) d}$ und der entsprechenden Molekularrefraktion in der nachstehenden Tabelle 8 zusammen. 
Ober d. Einfluss d. einfachen u. d. sogenannten mehrfachen Bindung etc. 327

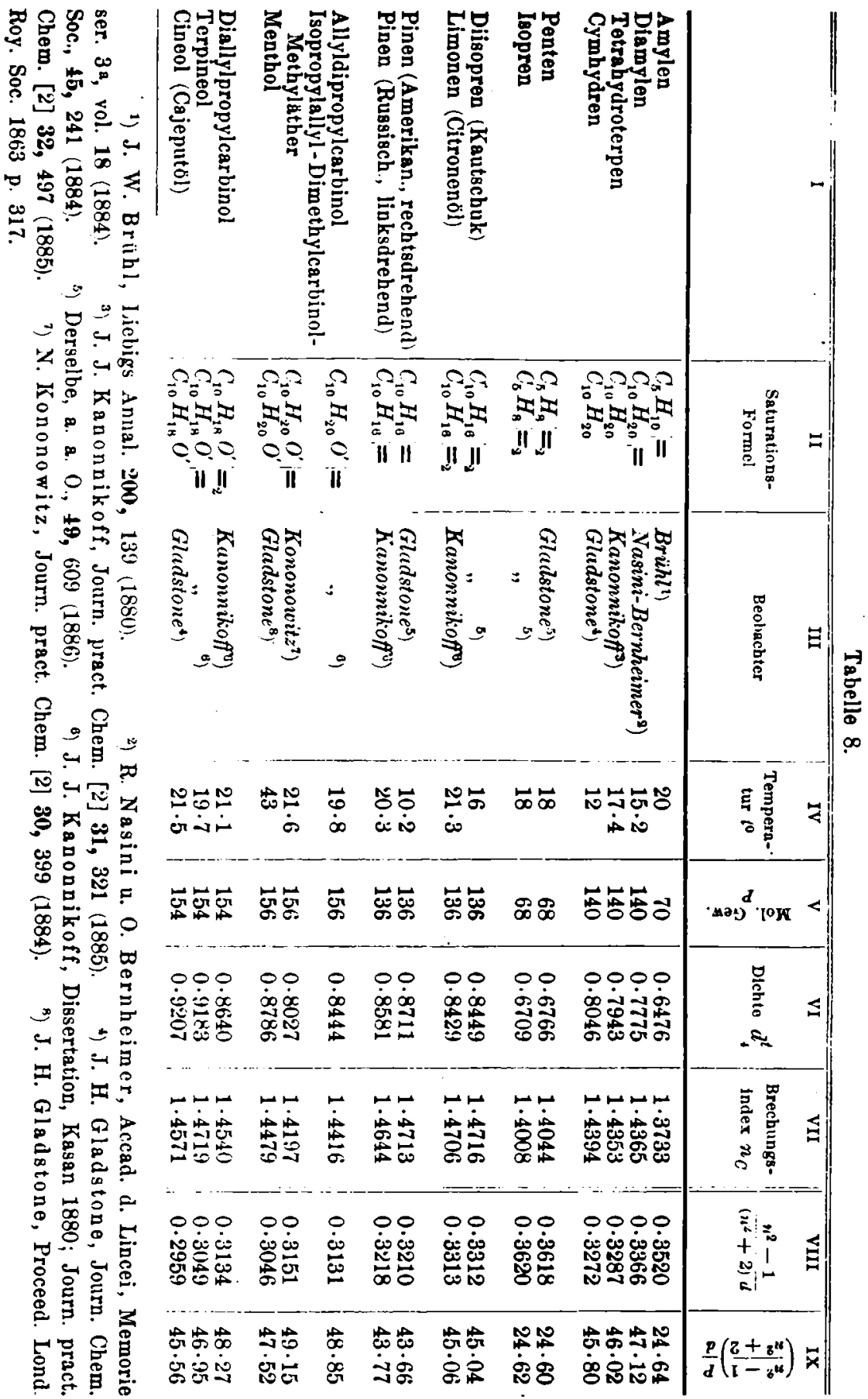


In der ersten Spalte findet man hier und da neben dem Namen noch eine nähere Angabe, betreffend Abstammung oder Eigenschaften der Körper. Die zweite Kolumne enthält das chemische Symbol, welches ich im Anschluss an die Bezeichnung ,empirische" und „Konstitutionsformel" die ,Saturationsformel" nennen möchte, da dieselbe ausser der molekularen Zusammensetzung den Sättigungszustand der Verbindungen anzeigt.

Eine Vergleichung der Dichte oder des Brechungsindex der polymeren und isomeren Körper, so wertroll dieselbe zur Feststellung von Identität oder Isomerie sein würde, muss hier unterbleiben, da diese Konstanten sehr bedauerlicher Weise bei den verschiedenen Verbindungen nicht bei übereinstimmender Temperatur gemessen worden sind. Wir wenden uns daher gleich zur Betrachtung des von der Temperatur nahezu unabhängigen spezifischen Brechungsvermögens in Kol. VIII.

Vergleicht man zunächst stellungsisomere Körper untereinander, wic das Diisopren und Limonen, $C_{10} H_{16}={ }_{2}$, das rechts- und das linksdrehende Pinen, $C_{10} H_{16}=$, und endlich die beiden olefinischen Verbindungen von der gemeinsamen Formel $C_{10} H_{20} O^{\prime}=$, so ergiebt sich bei diesen Isomeren eine grosse Ubereinstimmung der spezifischen Refraktion. Die Abweichungen sind entweder ganz verschwindend, erstrecken sich erst auf die vierte Dezimale, oder sie erreichen doch höchstens zwei Einheiten der dritten, überschreiten also in keinem Falle die zulässigen Beoachtungsfehler. Bei gleich saturierten, das ist positionsisomeren Substanzen übt also die verschiedene Gruppierung der Atome auf das spezifische (und natürlich auch das molekulare) Brechungsvermögen entweder gar keinen oder doch nur einen sebr geringen Einfluss aus, was ich übrigens schon früher an zahlreichen Beobachtungen nachgewiesen habe. Es lässt sich dahor aus dem Brechungsvermögen des Pentens und Isoprens oder aus demjenigen des Tetrahydroterpens und Cymhydrens, welches ebenfalls nur innerhalb der erwähnten Grenzen variiert, nicht feststellen, ob die betreffenden Verbindungen von gleichem Molekulargewicht ident oder stellungsisomer sind.

Vergleicht man nun sättigungsisomere Körper, wie Diamylen, $C_{10} I I_{20}=$, und Tetrahydroterpen oder Cymhydren, $C_{10} H_{20}$ : oder die 'Terpene $C_{10} H_{16}={ }_{8}$ mit den Pinenen $C_{10} H_{16}{ }^{\prime}=$ u. s. w., so crgiebt sich in allen Fällen eine sehr beträchtliche Verschiedenheit des spezifischen Brechungsvermögens; und zwar differiert diese Konstante stets in der Weise, dass der an Äthylenbindungen reichere Körper die grössere Refraktion besitzt: Der Unterschied beträgt ungefähr eine Einheit der zweiten Dezimale. Besonders bemerkenswert ist die letzte Gruppe sauerstoffhaltiger Isomerer. Mau findet das Brechungsvermögen des Diallylpropylearbinols, 
Ūber d. Einfluss d. einfachen u. d. sogenannten mehrfachen Bindung otc. 329 $C_{10} H_{18} O^{\prime}={ }_{8}$, mit zwei Äthylenbindungen, um circa 0,01 grösser als dasjenige des Terpineols, $C_{10} H_{18} O^{\prime}=$, mit einer solchen, und dasjenige des Terpineols wieder um annähernd 0,01 grösser als das Brechungsvermögen des Cineols, $C_{10} H_{18} O^{\prime}$, welches gar keine Äthylenbindungen mehr enthält.

Die angeführten Beobachtungen bestätigen also aufs neue das schon früher ron mir aufgestellte Gesetz:

Stellungsisomere Körper besitzen nahezu identisches Refraktionsvermögen, sättigungsisomere dagegen verschiedenes, und zwar ist die Differenz annähernd konstant bei konstantem Unterschiede in der Sättigungskapazität (disponiblen Affinität).

Es ergiebt sich ferner unmittelbar aus den Thatsachen, dass $z$ wei einfache Bindungen einer sogenannten doppelten oder Äthylenbindung nicht optisch gleichwertig sind. Denn die sättigungsisomeren Körper, wie z. B. Diamylen, $C_{10} I_{20}=$, und Tetrahydroterpen, $C_{10} H_{20}$, oder Limonen, $C_{10} H_{16}=2$, und Pinen, $C_{10}^{\prime} H_{16}=$ u. s. w. unterscheiden sich ja voneinander dadurch, dass für die Äthylenbindungen in der einen die doppelte Anzahl cinfacher Bindungen in der anderen Substanz vorhanden sind. Das Brechungsvermögen dieser Süttigungsisomeren ist aber nicht gleich, wie es sein müsste, wenn zwei einfache Atomverkettungen einer Äthylenbindung optisch äquivalent wären.

Das Verhalten der polymeren Körper führt zu demselben Resultat: wenn man gleiche Gewichtsmengen derselben, in welchen immer eine verschiedene Anzahl von Äthylengruppen vorkommt, vergleicht. Das spezifische Brechungsvermögen ist dann bei den Polymeren wie bei Sättigungsisomeren nicht nur stets verschieden, sondern es ändert sich für einen konstanten Unterschied in der Zusammensetzung ebenfalls um einen annähernd konstanten Betrag im Brechungsrermögen, welcher bei den Polymeren etwas grösser ist als bei den Sättigungsisomeren und ungeführ 0.012 bis 0.015 für je eine $\ddot{X}$ thylenbindung ausmacht.

Die hier erörterten Relationen des spezifischen Brechungsvermögens müssen sclbstverständlich auch für das molekulare ein Analogon finden.

Es ist aber von grösserem Interesse, diese letzteren Beziehungen eingehender zu untersuchen, indem die beobachteten Werte der Molekularbrechung unmittelbar mit der aus der chemischen Zusammensetzung der Körper sich ergebeuden Summe der Atomrerefaktion vergleichbar sind.

Dass die Molekularbrechung Stellungsisomerer nahezu identisch, diejenige Sättigungsisomerer dagegen verschieden ist und für einen gleichen Unterschied im Sättigungszustande einen annähernd konstanten Unterschied in der Molekularrefraktion zeigen muss, ergiebt sich aus dem vor- 
her beziiglich des spezifischen Brechungsvermögens Gesagten von selbst und ein Blick auf die Kolumne IX der Tabelle 8 bestätigt es. Würde optische Äquivalenz zwischen der sogen. doppelten und zwei einfachen Atombindungen statthaben, so müssten Saturations- ebenso wie Positionsisomere übereinstimmende Molekularbrechung besitzen. Dies ist nicht der Fall, die erwähnte Äquivalenz existiert also nicht. Findet dagegen Refraktionszunahme nur durch unbefriedigte Sättigungskapazität, das ist sogen. mehrfache Atombindungen, statt, so müssen Körper, in denen derartige Bindungen fehlen, stets annähernd diejenige Molekularbrechung zeigen, welche sich aus der empirischen Zusammensetzung ergiebt, gleichguiltig ob nun die betreffende Substanz der Paraffinreihe $C_{u} H_{2 n+9}$ oder irgend einer anderen von der allgemeinen Formel $\left(C_{n} H_{2 n+z}\right)-x H_{z}$ angehört. Ein Refraktionszuwachs wird dann nur in solchem Masse stattfinden, als disponible Affivitäten vorhanden sind. Da, wie Eingangs dieser Abhandlung nachgewiesen wurde, das durchschnittliche Refraktionsäquivalent der Äthylenbindung $r=$ ungefälır 1,78 betrïgt, so werden die Verbindungen $\left(\mathrm{C}_{n} \mathrm{H}_{2 n+2}\right)-x \mathrm{H}_{8}$ (falls die Annahme von dem Einfluss der Sättigungskapazität der Wirklichkeit entspricht) eine Molekularrefraktion ausüben, welche don aus der empirischen Formel sich ergebenden Wert $R$ um so viel mal 1,78 übertrifft, als Äthylengruppen vorhanden sind. Das Refraktionsinkrement wird also $z \cdot r=$ oder $z \cdot 1,78$ betragen, wenn $z$ die Anzahl vorhandener Äthylenbindungen darstellt. Dic folgende Tabelle lehrt, inwieweit diesen theoretischen l'ostulaten durch die Beobachtung entsprochen wird.

Tabelle 9.

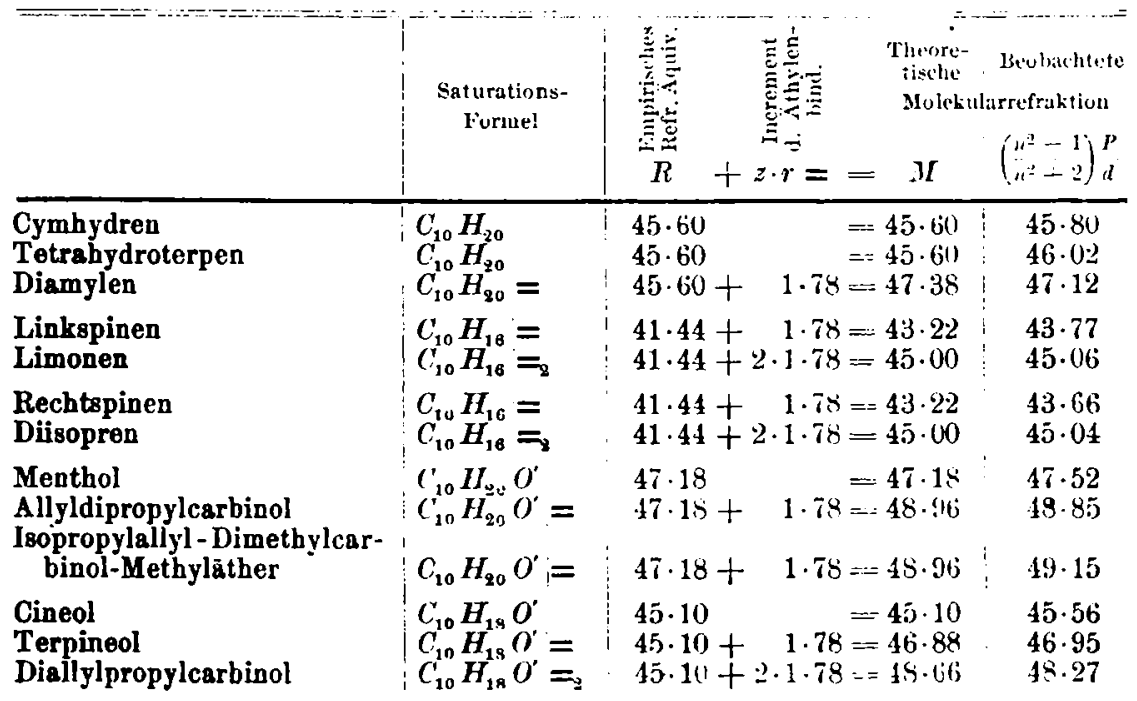


Über d. Einfluss d. einfachen u. d. sogenannten mehrfachen Bindung etc. 331

Man findet zunächst, dass den vier Verbindungen: Cymhydren, Totrahydroterpen, Menthol und Cineol, in denen, obwohl sie nach der Formel $\left(C_{n} H_{2 n+2}\right)-H_{2}$ bezw. $\left(C_{n} H_{2 n+2}\right)-2 H_{2}$ zusammengesetzt sind, doch keine Athylengruppe vorhanden ist, auch kein Refraktionsinkrement entspricht. Dio beobachtete Molekularbrechung ist identisch oder nahezu identisch mit dem aus der empirischen Formel folgenden Werte $R$, wio es die Theorie verlangt. $R$ und $M, \mathrm{~d}$. h. empirisches Refraktionsäquivalent und theoretische Molekularrefraktion, sind also in diesen Fällen gleich. Es zeigt sich freilich bei allen vier der aromatischen Reihe angehörigen Substanzen, dass die beobachtete Molekularbrechung etwas grösser ist als die theoretische, indessen erreicht dieser Uberschuss in maximo den Betrag von 0,46 und überschreitet also in keinem Falle dio zulässigen Fehlergrenzen. Dic Gruppierung der Atomo zu ringförmigen Gebilden kann also auf die Molekularbrechung dieser Körper jedenfalls nicht von beträchtlichem Einfluss sein.

Bei allen Körpern dagegen, in welchen Äthylenbindungen vorkommen, finden wir ein Refraktionsinkrement, und es ist der Anzahl derselben sehr nahe proportional. Die beobachtete Molekularbrechung stimmt in der That mit der theoretischen $M=R+z \cdot r=$ in allen Fällen befriedigend, in den meisten sogar vorzüglich übercin.

Von besonderem Wert ist nun auch die Vergleichung der Molekularrefraktion polymerer Verbindungen. Das disponible Material ist in der nachstehenden Tabelle 10 vereinigt.

Tabelle 10.

\begin{tabular}{|c|c|c|c|c|}
\hline & $\begin{array}{c}\text { Saturationsformel } \\
\text { für } \\
\text { gleiche ciewichtsmengen d. Körper }\end{array}$ & $\begin{array}{l}\left(\frac{n^{2}-1}{n^{2}+8}\right) \frac{P}{d} \\
\text { beobachtet }\end{array}$ & Differenz & $\begin{array}{c}\text { Theorie } \\
\quad \boldsymbol{M} \\
=R+z \cdot 1 \cdot 78\end{array}$ \\
\hline $\begin{array}{l}\text { Amylen } \\
\text { Diamylen }\end{array}$ & $2\left(r_{\mathrm{s}}^{\prime} H_{10} \Rightarrow\right)={ }^{C_{10} H_{20}=}$ & $\begin{array}{l}49 \cdot 28 \\
47 \cdot 12\end{array}$ & $2 \cdot 16$ & $\begin{array}{l}49 \cdot 16 \\
47 \cdot 38\end{array}$ \\
\hline $\begin{array}{l}\text { Isopren } \\
\text { Diisopren }\end{array}$ & $\begin{aligned} 2\left(C_{5}^{1} J_{\mathrm{s}}=_{2}\right)=C_{10} H_{1 \mathrm{~d}}= \\
C_{10} H_{16}={ }_{2}\end{aligned}$ & $\begin{array}{l}49 \cdot 24 \\
45 \cdot 04\end{array}$ & $2 \cdot 2 \cdot 10$ & $\begin{array}{l}48 \cdot 56 \\
45 \cdot 00\end{array}$ \\
\hline $\begin{array}{l}\text { Penten } \\
\text { Limonen }\end{array}$ & $2\left(C_{3} H_{3}=_{2}\right)=C_{10} H_{10}=$ & $\begin{array}{l}49 \cdot 20 \\
45 \cdot 06\end{array}$ & $2 \cdot 2 \cdot 07$ & $\begin{array}{l}48 \cdot 56 \\
45 \cdot 00\end{array}$ \\
\hline $\begin{array}{l}\text { Amylen } \\
\text { Cymbydren }\end{array}$ & $2\left(C_{5}^{\prime} H_{10}=\right)=\underset{C_{10} H_{20} H_{20}}{C_{2} H_{2}}$ & $\begin{array}{l}49 \cdot 28 \\
45 \cdot 80\end{array}$ & $2 \cdot 1 \cdot 74$ & $\begin{array}{l}49 \cdot 16 \\
45 \cdot 60\end{array}$ \\
\hline $\begin{array}{l}\text { Isopren } \\
\text { Linkspinen }\end{array}$ & $\begin{aligned} 2\left(C_{5}^{\prime} H_{8}={ }_{2}\right)= & C_{10} H_{10}= \\
& C_{10}^{\prime} H_{18}=\end{aligned}$ & $\begin{array}{l}49 \cdot 24 \\
43 \cdot 75\end{array}$ & $3 \cdot 1 \cdot 82$ & $\begin{array}{l}48 \cdot 56 \\
43 \cdot 22\end{array}$ \\
\hline $\begin{array}{l}\text { Penten } \\
\text { Rechtspinen }\end{array}$ & $2\left(C_{5} H_{5}==_{2}\right)={ }_{10} C_{10} H_{10}=$ & $\begin{array}{l}49 \cdot 20 \\
43 \cdot 66\end{array}$ & $3 \cdot 1 \cdot 85$ & $\begin{array}{l}48 \cdot 56 \\
43 \cdot 22\end{array}$ \\
\hline
\end{tabular}


Gleiche Gewichtsmengen polymerer Körper, z. B. zwei Molekel Amylen, $2\left(C_{5} H_{10}{ }^{\prime}=\right)=C_{10} H_{80}=8$ und eine Molekel Diamylen, $C_{10} H_{20}=$, stehen zu einander in dem Verhältnis Saturationsisomerer. Sie haben gleiche empirische Zusammensetzung und unterscheiden sich nur in der Sättigungskapazität, d. i. Art und Zahl der Atombindungen.

Denn bleiben wir z. B. bei den Kohlenwasserstoffen, also den einfachsten Körpern, so ist die Zusammensetzung derselben ausdrückbar durch die allgemeine Formel

$$
\left(C_{n} H_{z} n+2\right)-x I_{2} \text {. }
$$

Enthält ein Kohlenwasserstoff nur einfache Kohlenstoff bindungen, so sind deren

$$
n-1+x
$$

vorhanden; iu den Paraffinen also $n-1$, weil $x=0$, in den einfachen Ringen, wic Trimethylen, $n$, weil $x=1$ u. s. w.

Kommen dagegen Äthylenbindungen vor, so sind für jede derselben zwei einfache Kohlenstoffbindungen weniger vorhanden. Bczeichnet $z$ die Zahl dieser Äthylenbindungen, so giebt die allgemeine Formol

$$
n-1+x-2 z
$$

die Zahl der einfachen Kollenstoffverkettungen an.

Stellen wir diese durch das Zeichen -, die doppelte orler Äthylenbindung aber wie bisher durch $=$ dar, so findet man durch eine kurze Uberlegung, dass in zwei Molekeln Amylen

$$
C_{10} H_{20}-{ }_{6}=
$$

in einer Molekel Diamylen aber

$$
G_{10} H_{z 0}-{ }_{8}=
$$

d. h. für eine Äthyleubindung weniger, zwei einfache Bindungen mehr vorhanden sind. Gleiche Gewichtsmengen dieser und aller anderen Polymeren stehen also zu einander in dem Verhältnis saturationsisomerer Substanzen, wie z. B. Limonen, $C_{10} H_{16}:={ }_{2}$, zu Pinen, $C_{10} H_{16}=$

Man wird daher erwarten dürfon, dass sich bei dem Vergleich der Molekularrefraktion polymerer Verbindungen die nämlichen Beziehungen ergeben, welche bei den Saturationsisomeren stattfinden. End dies ist in der That der Fall.

Dass die Molekularrefraktion gleicher Gewichtsmengen Polymerer in keinem Falle identisch ist - wie sie doch sein sollte, wenn zwei einfache einer Äthylenbindung optisch äquivalent wären - ergiebt sich auf den 
Uber d. Einfluss d. einfachen n. d. sogenannten mehrfachen Bindung etc. 333 ersten Blick aus der rorstehenden Tabelle 10, und es geht dies ja auch unmittelbar aus dem vorher erwähnten Verhalten des spezifischen Brechungsvermögens hervor.

Vergleicht man nun die beobachtete Molekularrefraktion der Polymeren, so zeigt sich, dass die in der Tabelle enthaltenen sechs Paare in zwei Gruppen zusammentreten.

Die erste derselben illustriert den einfachsten Vorgang der Polymerisation, welcher darin besteht, dass zwei Molekeln unter Aufhebung der Hälfte vorhandener Äthylenbindungen zu einem komplexen Gebilde vereinigt werden. Der optische Effekt ist von einer merkwürdigen Regelmässigkcit: Für jede aufgehobene Äthylenbindung nimmt die Molekularrefraktion um durchschnittlich $2 \cdot 11 \mathrm{ab}$.

Die andere Gruppe stellt einen fortgeschrittneren Grad der Polymerisation dar: Bei dem Zusammentritt zweier Molekeln wird mehr als die Hälfte vorhandener $\ddot{\Lambda}$ thylenbindungen aufgelöst. Die Folge ist wieder eine auffallend konstante Abnahme der Molekularbrechung, welche indessen hier etwas kleiner ist als in der ersten Gruppe und durchschnittlich 1.80 für jede verschwundene Äthylenbindung ausmacht.

Durch die grosse Regelmässigkeit in der Refraktionsabnahme bei beiden Gruppen wird man auf den Gedanken gefübrt, dass der auf Auslösung einer $\ddot{A}$ thylenbindung fallende Betrag dieser Verminderung nicht ganz konstant ist, sondern langsam abnimmt, je mebr Äthylenbindungen aufgehoben werden. Dafür spricht ferner, dass in der ersten Gruppe, in welcher die Hälfte der Äthylenbindungen beseitigt wird, die Refraktionsdekadenz im Mittel 2.11, bei den beiden letzten Paaren der zweiten Gruppe, wo drei Viertel der Äthylenbindungen sich lösen, dieser Wert durchschnittlich 1.83 beträgt, während er bei Amylen - Cymhydren, wo sämtliche Äthylenbindungen verschwinden, nur noch 1.74 erreicht. Es ist möglich und würde nicht überraschend sein, dass in der That eine so geartete Verminderung des Refraktionswertes unter den angegebenen Umständeu stattfinden muss und bei den vorstehonden Beispielen nicht zufällig ist. Es würde dies nur von neuem bestätigen, dass die Atomkonfiguration auf die Molekularbrechung der Körper nicht ohne jeden Einfluss ist und daher der Refraktionswert der Ätlylenbindung auch bei den Polymeren wie bei allen übrigen Körpern keine absolute Konstante darstellt, sondern nur einem mittleren Werte, als welcher $r==1.78$ angenommen wurde, sich mehr oder minder nähert.

Vergleicht man nun die mit Hilfe dieses durchschnittlichen Refraktionsinkrementes abgeleitete theoretische Molekularbrechung $\boldsymbol{M}=\boldsymbol{R}+$ 
8.1,78 mit der beobachteten, so ergiebt sich, wie aus Tabelle 10 ersichtlich, eine recht genügende Ubẹreinstimmung in allen Fällen.

\$8.

In dem Verhältnis polymerer Verbindungen stehen auch Cymhydren und Tetrahydroterpen zu Äthylen. Und um so bedeutungsvoller wird hier eine optische Vergleichung werden, als der Aggregatzustand der Körper ein verschiedener ist. . Die beiden erstgenannten sind im flüssigen, das Äthylen im Gaszustande untersucht worden. Eine besondere Beachtung gebührt diesen Substanzen aber auch deshalb, weil im Cymhydren und Tetrahydroterpen gar keine doppelten, im Äthylen dagegen keine einfachen Kohlenstoffbindungen vorkommen. Die Molekularzusammensetzung der beiden ersteren Körper wird ausgedrückt durch die Saturationsformel

$$
C_{10} H_{20}-{ }_{10} \text {, }
$$

während einer gleichen Gewichtsmenge Äthylen die Formel

zukommt.

$$
5\left(C_{2} H_{4}=C_{10} H_{20}=\right.
$$

Die Polymerisation von Äthylen zu Cymhydren oder Tetrahydroterpen entspricht der Umwandlung von Aldehyd zu Paraldehyd, oder von Äthylen zu Hexahydrobenzol. In der That sind ja Cymhydren und Tetrabydroterpen wahrscheinlich identische oder stellungsisomere Hexahydrocymole, während der Paraldehyd als Abkömmling des Hexalydromesitylens aufgefasst werden kann: ${ }^{1}$ )

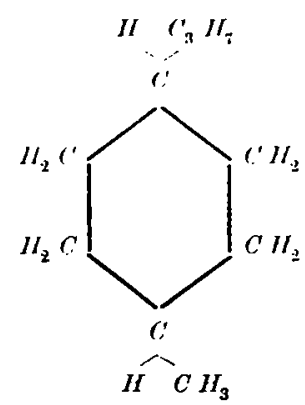

Cymhydren und Tetrahydroterpen

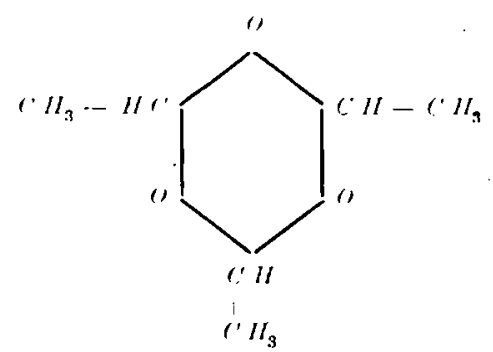

Paraldehyd

Die Polymerisation besteht in allen drei Fällen ${ }^{2}$ ) in einer vollständigen Auslösung der doppelten und Umwandlung in einfache Atombindungen.

2) Er steht zu letzterem in ahnlicher Beziehung wie Piperidin zu Hexahydrobenzol. 9) Dass nur die Polymerisation von Acetaldehyd faktisch ausgefürt worden ist, bleibt natürlich für unsere Betrachtung irrelevant. 
Uber d. Finfluss d. einfachen u. d. sogenannten mebrfachen Bindang etc. 335

Die „brechende Kraft“ $(n-1)$ des Athylengases, gegen die der Luft gleich 1 gesetzt, wurde nun von Mascart ${ }^{1}$ ) für Natriumlicht bestimmt und zu 2.46 gefunden. Legt man als zu vergleichenden Brechungsindex der Luft bei $0^{\circ}$ und atmosphärischem Druck den von Delambre ${ }^{2}$ ), Biot und Arago ${ }^{9}$ ), $\mathrm{Jamin}^{4}$ ) und Anderen übereinstimmend erhaltenen Wert 1.000294 für weisses Licht zu Grunde, so ergiebt sich für Äthylen bei denselben Druck- und Temperaturverhältnissen $n_{D}=1.000723 . .^{5}$ ) Setzt man für $d$ die theoretische Dichte des Äthylens bei $0^{\circ}$ und $760 \mathrm{~mm}$ Druck in Bezug auf Wasser von $4^{06}$ ), so sind alle nötigen Daten zur Ableitung der Molekularrefraktion vorhanden.

Für das Cymbydren und Tetrahydroterpen sind die Brechungsindices für die $D$-Linie ebenfalls bekannt, so dass man diese Substanzen mit dem Äthylen .unmittelbar optisch vergleichen kann. In der folgenden kleinen

1) Mascart. Compt. rend. 86, 1182 (1878). 2) Delambre, in Laplace, Mécanique céleste, 4, 237, 246, 272. Paris 1805; ferner, Mémoires d. l'Instit. d. France 7 (1806), im Jahresbericht von Delambre u. bei Biot u. Arago, vergl. 3. 3) Biot u. Arago, Mím. d. l'Instit. 7, 301. 4) Jamin, Annal. chim. phys. (3) B9, $282(1860)$.

5) In einer kürzlich veröffentlichten Arbeit [Liebigs Annal. $\mathbf{9 3 5}, 83$ (1886)] habe icb für den Brechungsindex bei $12^{\circ}$ einen etwas zu grossen Wert angegeben. Auch der dort mitgeteilte Index für Acetylen ist nicht ganz genau und ebenfalls zu gross. (Man vergleiche weiter unten). Dem entsprechend bedürfen auch die a. a. 0 . angeführten Zahlen für die Molekularrefraktion einer Korrektur.

Streng genommen sollte der zu ermittelnde Brechungsindex $n_{D}$ des Äthylengases nicht mit Hilfe desjenigen der Luft für weisses Licht, sondern mittelst des ebenfalls für die Linie $D$ geltenden abgeleitet werden. Der Einfluss dieser Ungenauigkeit.auf den so abgeleiteten Index $n_{D}$ ist indessen unmerklich und wüde sich erst in der nicht mehr in Betracht kommenden siebenten Dezimale zu orkennen geben. So fand z. B. Mascart, [Compt. rend. 78, 617 u. 679 (1874) und Annal. École Normale (2) (6, 1 (1877)] den Brechungsindex der Luft für weisses Licht zu 1.0002927, für dic Linic $D$ zu 1.0002923. Ketteler (Farbenzerstreung der Gase, Bonn 1865 S. 85) giebt fïr $n_{D}$ den Wert 1.0002947 , welcher mit demjenigen für weisses Licht von Delambre, Biot u. Arago und Jamin in den secbs ersten Dezimalen übereinstimmt. Dagegen findet L. Lorenz [Wiedem. Ann. 11, $89\left(1880\right.$ i) $n_{D}=1.0002911$. Praktisch und für chemische Zwecke ist es nun ziemlich gleichgültig, welchen dieser rerschiedenen und schon in der sechsten Dezimale nicht ganz sicheren Werte für den Brechungsindex $n_{D}$ der Luft man zu Grunde legt. Der Einfluss dieser geringen Abweichungen anf die Molekularrefraktion ist ganz unwesentlich und liegt durchaus innerhalb der durch anderveitige Versuchsfehler verursachten Ungenauigkeiten. Ich bleibe daher bei dem mittleren Werte $n=1.000294$, den ich auch als den Brechungsindex der Luft fúr die $D$ Linie setze.

6) Dichte des Wasserstoffs bei $\left({ }^{\circ} \mathrm{C} .760 \mathrm{~mm}\right.$ Druck n. $45^{\circ}$ geograph. Breite in Bezug auf Wasser: 0.000089523 (Landolt-Bornstein, Tabellen S. 76). 
Tabelle 11 sind für alle drei Körper die entsprechenden Daten zusammengestellt.

Tabelle 11.

\begin{tabular}{|c|c|c|c|c|c|c|c|}
\hline & $\begin{array}{l}\text { Saturat. } \\
\text { Formel }\end{array}$ & $\begin{array}{l}\text { Tempe- } \\
\text { ratur }{ }^{n}\end{array}$ & $\begin{array}{l}\text { Mol. } \\
\text { (iew. P }\end{array}$ & $\begin{array}{l}\text { Dichte } \\
d_{t}^{t}\end{array}$ & $\begin{array}{c}\text { Brechungs:- } \\
\text { index } \\
n l\end{array}$ & 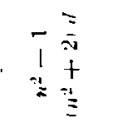 & $\begin{array}{l}3= \\
3=1 \\
1+1 \\
=13\end{array}$ \\
\hline $\begin{array}{l}\text { Āthylen } \\
\text { Cymhydren } \\
\text { Tetrahydroterpen }\end{array}$ & $\begin{array}{l}C_{9} H_{4}= \\
C_{10} H_{20} \\
C_{10} H_{\geq n}\end{array}$ & $\begin{array}{l}0 \\
12 \\
17 \cdot 4\end{array}$ & $\begin{array}{r}28 \\
140 \\
140\end{array}$ & $\begin{array}{l}0.0012509 \\
0.8046 \\
0.7943\end{array}$ & $\begin{array}{l}1.000723 \\
1.4417 \\
1.4375\end{array}$ & $\begin{array}{l}0.3854 \\
0.3287 \\
0 \cdot 3302\end{array}$ & $\begin{array}{l}10 \cdot 79 \\
46 \cdot 02 \\
46 \cdot 22\end{array}$ \\
\hline
\end{tabular}

Vergleicht man das in der vorletzten Spalte enthaltene spezifische Brechungsvermögen dieser Körper, so ergiebt sich ungeachtet des verschiedenen Aggregatzustandes derselben ganz das nämliche, was wir bisher bei den polymeren und den saturationsisomeren Verbindungen kennen gelernt haben. ${ }^{1}$ ) Wir fanden, diss durch die Polynerisation das Brechungsvermögen abnimmt, und zwar für jede aufgehobene Athylenbindung um ungefähr 0.012 bis 0.015 , während bei den Sättigungsisomeren eine durchschnittliche Verminderung von 0.01 fïr jede ausgelöste $\mathrm{A}$ thylenbindung konstatiert wurde. Beim Utbergang von Athylengas zu Cymhydren oder Tetrahydroterpen: $5\left(\left(_{2} H_{4}=\right)=C_{10} H_{20}-_{10}\right.$, wobci fünf Doppelbindungen verschwinden und dafür zehn einfache entstehen, beträgt nun die Verminderung des spezifischen Brechungsrermögens, wie aus Tabelle 11 ersichtlich, ungefähr $5 \cdot 0,011$.

Eine Vergleichung der in Bezug auf die Linic I) beobachteten Molekularrefraktion des Äthylengases mit der theoreti schen, fïr den Strahl $C$ gültigen, wäre nicht strenge richtig; obwohl der Fehler wegen der jedenfalls nur geringen Dispersion des $\ddot{A}$ thylens kein wesentlicher sein könnte. Indessen wird man auch diesen kleinen Fehler fast vollständig vermeiden, wenn man annimmt, dass die bisher noch unbekannte Dispersion des

1) Die Refraktionskonstante, $\left(\frac{n^{2}-1}{n^{2}+2}\right) \frac{1}{d}$, welche anch als Näherungsausdruck für das wahre spezifische Volumen gelten darf, gestattet also eine Vergleichung desselben bei allen Aggregatzuständen, während das gewöbnliche oder scheinbare spezifische Volumen, $\frac{1}{d}$, nur bei gleichem Aggregatzustande der Körper rergleichbar ist. Die allgemeinere Auwendbarkeit jener das Refraktionsvermögen und das wahre spezifische Volumen ausdrückenden Konstante darf gewiss als ein grosser Vorzug derselben bezeichnet werden. Man vergl. J. W. Brühl, Ber. Deutsch. Chem. Gesell., 19, S. 2746 (1886). 
Ôber d. Einfluss d. einfachen u. d. sogenannten mehrfachen Bindung etc. 337

Äthylens derjenigen des verwandten Amylens gleich ist - eine Annahme, welche jedenfalls der Wahrheit sehr nahe kommt. Unter dieser Voraussetzung lässt sich die Molekularrefraktion des Äthylens für die Linie $C$ ermitteln, indem man zunächst untersucht, in welchem Maasse die für $C$ und für $D$ beobachtete Molekularbrechung beim Amylen differiert. Es ergiebt sich dies aus folgender Zusammenstellung.

Tabelle 12.

\begin{tabular}{|c|c|c|c|c|c|c|c|c|}
\hline & \multirow[t]{2}{*}{$\begin{array}{l}\text { Eimpiri- } \\
\text { sche } \\
\text { Formel }\end{array}$} & \multirow[t]{2}{*}{$\begin{array}{c}\text { Hol. } \\
\text { (iew. } \\
P\end{array}$} & \multirow[t]{2}{*}{$\begin{array}{c}\text { Dichte } \\
i^{m}\end{array}$} & \multicolumn{2}{|c|}{ Brechungsindices } & \multicolumn{2}{|c|}{$\begin{array}{c}u^{2}-1 \\
\left(u^{2}+y\right) d\end{array}$} & $\left(a^{2}-1\right) \frac{p}{d}$ \\
\hline & & & & $n_{C}$ & $n_{D}$ & $n_{c}$ & $n_{D}$ & $n_{C} \mid n_{D}$ \\
\hline Amylen & $C_{5} H_{10}$ & 70 & 0.6476 & $1 \cdot 3733$ & 1.3758 & 0.352 & 0.3542 & $24.64: 24.79$ \\
\hline
\end{tabular}

Das spezifische und das molekulare Brechungsvermögen des Äthylens für den Strahl (' lässt sich nun aus dem bekannten für $D$ und mit Hilfe der vorstehcnd für Amylen angeführten Werte durch einfache Proportionsrechnung ableiten. Man erhält auf diese Weise für die Molekularrefraktion den Wert 10.73, während sich in Bezug auf die Linie $D 10.79$ ergeben hatte.

Die Vergleichung mit der theoretischen Molekularrefraktion liefert rlann das folgende Resultat:

Tabelle 13.

\begin{tabular}{|c|c|c|c|c|}
\hline & \multirow[b]{2}{*}{$\begin{array}{l}\text { Saturations- } \\
\text { Fonuel }\end{array}$} & \multicolumn{3}{|c|}{$\begin{array}{c}\text { Theoretische } \\
\text { MolekularreJraktion }\end{array}$} \\
\hline & & & $+r===M$ & $\left(\begin{array}{c}2 \\
2 \\
2\end{array}\right)^{2}$ \\
\hline Äthylen & $r_{2} H_{4}=$ & $9 \cdot 1$ & $2+1.78=10 \cdot 90$ & 10.73 \\
\hline
\end{tabular}

Die Ubereinstimmung der theoretischen und der beobachteten Molekularbrechung ist, wie man sieht, eine sebr befriedigende.

Anstatt des durchschnittlichen Refraktionsinkrements der Doppelbindung, $r==1.78$, findet man beim Äthylen $10.73-9 \cdot 12=1.61$. Es ist nun zu erwarten, dass bei der Polymerisation von fünf Molekeln Äthylen zu einer Molekel Cymhydren oder Tetrahydroterpen die Molekularbrechung um annähernd den fünffachen Betrag jenes Inkrements abnimmt. Und dies ist thatsächlich der Fall, wie ein Vergleich der sowohl für den Strahl $C$ als $D$ festgestellten Refraktionswerte übereinstimmend ergiebt: 
Tabelle 14.

\begin{tabular}{|c|c|c|c|c|c|}
\hline & $\begin{array}{l}\text { Saturations- } \\
\text { Fonuel }\end{array}$ & $\left(\begin{array}{c}c \\
\left(\begin{array}{c}n^{2}-1 \\
n^{2}+2\end{array}\right)_{d}^{P}\end{array}\right.$ & Differenz & $\left(\begin{array}{c}D \\
n^{2}-1 \\
n^{2}+2\end{array}\right) \frac{P}{d}$ & Differenz. \\
\hline $\begin{array}{l}5 \mathrm{Mol} . \text { Äthylen }=5\left(C_{z} H_{4}=\right) \\
1 \text { Cymbydren }\end{array}$ & $\begin{array}{l}C_{10} H_{90}=5 \\
C_{10} H_{20}-10\end{array}$ & $\begin{array}{l}53 \cdot 65 \\
45 \cdot 80\end{array}$ & $5 \cdot 1,5 \pi$ & $\begin{array}{l}53.95 \\
46.02\end{array}$ & $5 \cdot 1,09$ \\
\hline $\begin{array}{l}5 \mathrm{Mol} . \text { Āthylen }=5\left(C_{q} H_{4}=\right) \\
1 " \text { Tetrabydroterpen }\end{array}$ & $\begin{array}{l}C_{20} H_{20}= \\
C_{30}^{\prime} H_{20}=-10\end{array}$ & $\begin{array}{l}53 \cdot 65 \\
46 \cdot 02\end{array}$ & $5 \cdot 1,53$ & $\begin{array}{l}53 \cdot 95 \\
46 \cdot .22\end{array}$ & $5 \cdot 1,55$ \\
\hline
\end{tabular}

Es geht also aus dem molekkularen und aus dem spezifischen Brechungsvermögen des gasförmigen Äthylens und der ihm polymeren flüssigen Körper, wie aus allen vorher angefübrten Beispielen, unzweifelhaft hervor, dass eine sogenannte doppelte Bindung der Atome $\mathrm{zwei}$ einfachen niemals optisch äquivalent ist. Bei Umwandlung der ersteren in die anderen verschwindet das Refraktionsinkrement der Körper: gänzlich oder nur teilweise, je nachdem sämtliche mebrfachen Bindungen ausgelöst werden oder nur ein Teil derselben. Mag nun der Vorgang dicser Auslösung in einer Polymerisation, oder in einer Isomerisation (Umlagerung der Atome bei gleich bleibendem Molekulargewicht und $̈$ nderung der Saturationskapazität) bestehen - die optische Konsequenz ist dieselbe.

\section{$\S 9$.}

\section{Das fundamentale Refraktionsgesetz.}

Durch alle vorstehend angeführten Beobachtungen wird eine vor 17 Jahren von Gladstone ${ }^{1}$ ) auf Grund der damaligen noch sehr spärlichen Erfahrungen ausgesprochene oder vielmehr nur angedeutete Vermutung endgültig widerlegt. Nach derselben sollte nämlich der in den Reihen $\left(C_{n} H_{2 n+2}\right)-x H_{2}$ auftretende Refraktionsüberschuss eine einfache Folge des anwachsenden Kohlenstoffgehaltes sein.

Wäre dies richtig, so müsste allen Gebilden von der allgemcinen Formel $\left(C_{n} H_{2 n+2}\right)-x H_{2}$ ein Refraktionsinkrement zukommen. Dies ist aber keineswegs der Fall (Menthol, Cineol, Cymhydren u. s. w.).

Es sollten dann auch wohl die polymeren Körper, welche ja identische Flementarzusammensetzung besitzen, gleiches spezifisches. Brechungsvermögen zeigen und ibre Molekularrefraktion nur eine Funktion des Molekulargewichts sein. Auch dies trifft niemals zu.

') J. H. Gladstone, Journ. Chem. Soc [2] 8, 147 (1870). 
Gänzlich rätselhaft wäre es dann ferner, dass den Stellangsisomeren stets, den Sättigungsisomeren dagegen niemals gleiche Refraktion zukommt.

Demnach steht es unzweifelhaft fest, dass jene (von Hrn. Gladstone freilich auch nur sehr vorsichtig geäusserte) Vermutung unhaltbar ist. Seither ist sie übrigens von ihrem Urheber selbst längst verlassen worden. ${ }^{\text {) }}$

Die Erfahrung hat dagegen die 1879 von mir aufgestellte Hypothese, dass Körper von der allgemeinen Formel $\left(C_{n} H_{2 n+2}\right)-x H_{2}$ nur dann einen Brechungsüberschuss aufweisen, wenn in ihnen mehrfache Atombindungen rorkommen, gerechtfertigt. Und es hat sich bestätigt gefunden, dass ein eventueller Brechungszuwachs nur in dem Masse erscheint, als solche Bindungen vorhanden sind, d. h. annähernd proportional der Zahl und Art der vorhandenen ungesättigten Atomgruppen, während die verschiedene Konfiguration der Atome nur geringen Einfluss ausübt.

Durch die vorher mitgeteilten Beobachtungen scheint mir der unmittelbare experimentelle Nachweis des kausalen Zusammenhangs zwischen dem Refraktionsinkrement gewisser Körper und dem Zustande der Sättigungskapazität ihrer Atome erbracht worden zu sein. Eine andere Deutung der Thatsachen wäre wohl, so weit ich es zu übersehen vermag, gegenwärtig nicht möglich. In der Vorstellung von dem prinzipalen Einfluss der unvollständigen Sättigung (mehrfachen Bindung) der Atome auf das Lichtbrechungsvermögen der Körper dürfte zur Zeit das einzige Mittel geboten sein, sich überhaupt einen Einblick in die Refraktionserscheinungen zu verschaffen, und so, anstatt in rohem Empirismus umber zu tasten, eine theoretische Grundlage zu gewinnen, auf welcher die wissenschaftliche Forschung weiter bauen kann.

Ich halte es für zweckmässig, die im vorstehenden erörterten, zum

1) Herr $\mathrm{Nasin} \mathrm{i}$ hat sie indessen vor einigen Jahren wieder hervorgeholt (1884. Memor. d. Accad. d. Lincei, (3) 18) und das bestimmt mich, ihrer uberhaupt hier zu gedenken. Durch das Verhalten der Naphthalinabkömmlinge und ciniger anderer Körper von enormer Dispersion glaubt er sich zu dem Schlusse berechtigt, „dass eine einfache Beziehung zwischen den Refraktionsinkrementen und der chemischen Konstitution der Körper nicht vorhanden sei, und aus den Thatsaciven nur so viel mit Sicherheit hertorgehe, dass die Molekularrefraktion organischer Verbindungen mit wachsendem Kohlenstoffgehalt zunehme". Ich habe schon einmal Veranlassung genommen, die Irrigkeit dieser Ansichten nachzuweisen (Liebigs Annal. 235, 1 u. ff. [1886]). In einer kürzlich orschienenen Erwiderung (Rendiconti d. Accad. d. Lincei. 1887, 3, 128) beharrt jedoch Hr. Nasini auf seiner Meinung und er beschliesst seine Polemik mit der Wiederholung jenes eben angefuhrten Satzes. Derselbe erfăhrt nun durch alles hier mitgeteilte ein so grandliches Dementi, dass ich eine weitere Widerlegung nicht fór nüzlich erachten kann. Ich hoffe vielmehr, die Thatsachen werden Hrn. Nasini jetzt anerkennen lassen, dass er sich in Bezug auf seine Schlussfolgerungen im Irrtum befindẹt. 
Teil aber schon früher von mir aufgefundenen und hier durch ein neues Beobachtungsmaterial begründeten Regelmässigkeiten in kurzen Sätzen übersichtlich zusammen zu stellen.

1. Stellungsisomere Körper haben gleiches spezifisches und molekulares Refraktionsvermögen, Sättigungsisomere dagegen verschiedenes.

2. Polymere Verbindungen zeigen niemals gleiches spezifisches Brechungsvermögen oder den Molekulargewichten entsprechende multiple Molekularrefraktion.

3. Umwandlungen mehrfacher Bindungen der Atome in einfache hat stets Refraktionsverminderung zur Folge, gleichgültig, welcher Art der chemische Vorgang ist (Polymerisation oder Isomerisation).

4. Der optische Effekt der Aufhebung mehrfacher Bindungen ist auch derselbe, ob hierbei offene Atomketten resultieren (Amylen - Diamylen), oder ringförmige Gebilde mit einer Ringgruppe (Paraldehyd, Cymhydren, Menthol u. s. w.), oder mit mehreren Ringen (Pinene, Cyneol).

5. Die Molekularrefraktion wahrer gesättigter Körper ist sehr nahe gleich der aus der empirischen chemischen Formel folgenden Refraktionssumme der Atome, jedes derselben als einfach gebundenes gerechnet. Als gesättigte Körper sind alle diejenigen zu betrachten, in denen keine mehrfache Atombindung vorkommt, mögen dieselben nun echte Paraffine oder Abkömmlinge von der allgemeinen Formel $\left(C_{n} H_{2 n+2}\right)-x I_{2}$ darstellen.

6. Alle ungesättigten Körper zeigen ein Refraktionsinkrement, welches der Anzahl der vorhandenen Äthylen-, Acetylen- und Carbonyibindungen annäbernd proportional ist. Die Proportionalität trifft im grossen und ganzen um so genauer zu, je weniger sich die betreffenden Körper durch eine besonders intensive Dispersion auszeiclınen. ${ }^{1}$ )

Sämtliche hier angeführten Regeln können nun als spezielle Erscheinungsformen und Konsequenzen ein und desselben chemisch-optischen Grundgesetzes aufgefasst werden, welches ich schon früher aufgestellt habe und nunmehr folgendermaassen formuliere:

Die Atomrefraktion des Kohlenstoffs und die des Sauerstoffs ist keine unveränderliche, sondern sie variiert je nach der Befriedigung der Affinität. Bei ein und derselben Sättigung aber ist sie annthernd konstant und von der Konfiguration der Atome in den verschiedenen Verbindungen nur in geringem Grade abhängig. Die monovalenten Grundstoffe be-

1) Man vergleiche meine diesbezuglichen Abbandlungen: Liebigs Ann. 235, 1 und Ber. Deutsch. Chem. Gesell. 19, 2746 (1886). 
Über d. Einfluss d. einfachen u. d. sogenannten mehrfachen Bindung etc. 341 sitzen dagegen stabile oder doch nahezu unveränderlicho A tomrefraktion.

Die praktisch zur Anwendung kommenden Refraktionswerte (man vergleiche S. 311) können selbstverständlich keine genauen sein. Selbst dann wären sie es nicht, wenn die Gruppierung der Atome gänzlich einflusslos wäre. Sie werden sich vielmehr den wahren Durchschnittswerten nur nähern können, und das umsomehr, je reicher das zur Ableitung herangezogene Beobachtungsmaterial ist.

Bei Formulierung jenes chemisch - optischen Grundsatzes habe ich mich hinsichtlich der mehrwertigen Elemente mit Absicht auf den Kohlenstoff und Sauerstoff beschränkt. Denn nicht allein ist das Beobachtungsmaterial in Bezug auf andere Grundstoffe, wie z. B. Schwefel, viel zu dürftig, um irgend welche sicheren Schlüsse darauf basieren zu köunen, sondern es erscheint mir überhaupt wenig ratsam, das für Kohlenstoff und Sauerstoff erkannte ohne weiteres zu generalisieren. Es ist leicht möglich, und ich glaube sogar schon positive Anhaltspunkte dafür zu besitzen, dass die Natur auch hier nicht nach einer Schablone gearbeitet hat, sondern dass sich mannigfaltige Verbältnisse bei den verschiedenen Elementen vorfinden. Dass die wechselnde Valenz die alleinige oder auch nur hauptsächliche Ursache der auch bei andern mehrwertigen Grundstoffen beobachteten variablen Refraktion sei, liegt also zunächst keine Veranlassung vor zu behaupten. Wohl aber darf man es als wahrscheinlich hinstellen, dass, wo überhaupt derartige Variationen stattfinden, die Afffnitätsänderungen dabei einen wichtigen Faktor bilden. Es erscheint somit die Annahme zulässig, dass einwertige Elemente im wesentlichen konstante Atomrefraktion besitzen.

Diese Annahme habe ich bereits im Anfange meiner diesbezüglichen Untersuchungen zu begründen getrachtet. ${ }^{1}$ ) Es konnte auch in der That nachgewiesen werden, dass der Wasserstoff und die Halogene sehr nahe konstante Atomrefraktion besitzen, aus welchen organischen Verbindungen man diese Werte auch ableiten mochte. Die Abweichungen überschritten nie die möglichen Beobachtungsfehler.

Heute kann ich diesen Nachweis in wirksamster Weise vervollständigen. Denn es hat sich beim Studium der für die gasförmigen Körper vorliegenden Beobachtungen (von welchen ich in dieser Abhandlung bereits Gebrauch gemacht habe und noch weiter unten machen werde) herausgestellt, dass der Wasserstoff und das Chlor im freien Zustande, wie anch zu Chlorwasserstoffgas vereinigt, sehr nahe dieselbe Atomrefraktion.

1) J. W. Brühl, Liebigs Ann. 203, 1 (1880), 
besitzen, welche ihnen auch in den flüssigen organischen Verbindungen eigen ist.

Einer demnächst zu veröffentlichenden Arbeit über das Lichtbrechungsvermögen der Gase und Dämpfe entnehme ich vorläufig die folgenden Angaben.

Tabelle 15.

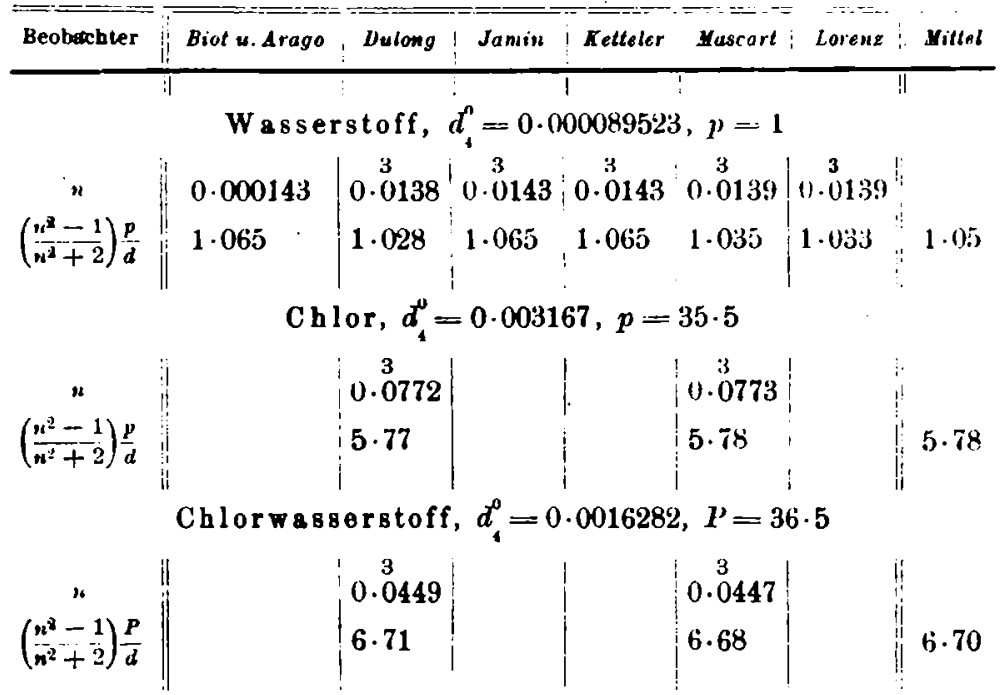

Der Brechungsindex $n$ (wie auch die Dichte $d$ stets bei $0^{\circ}$ und $760 \mathrm{~mm}$ Druck) bezieht sich bei den drei ersten Beobachtern auf weisses, bei den übrigen auf Natriumlicht. Wie man bemerkt, übt das hier auf die Atombezw. Molekularrefraktion keinen merklichen und gegenüber den Versuchsfehlern verschwindenden Einfluss aus. Ebensowenig würde ein Unterschied bemerkbar sein, wenn man rotes Licht, z. B. den Strahl $C$ oder die Lithiumflamme, benutzen würde, wie sich aus den Messungen ron L. Lorenz ${ }^{1}$ ) und Anderen ergiebt.

Man sieht nun, dass die Molekularrefraktion des Chlorwasserstoffgases, 6.70 , sehr annähernd gleich ist der Summe der Atomrefraktionen, welche den Elementen im freien Zustande zukommen: $1 \cdot 05+5 \cdot 78=6 \cdot 83$. Die Abweichung beträgt nur 2\%. Dieselbe überschreitet freilich, nach Dulongs ${ }^{2}$ ) Darlegung, die möglichen Beobachtungsfehler, indessen finden wir für den Wasserstoff selbst bei den verschiedenen Beobachtern Angaben von 1.028 bis 1.065 , also Differenzen bis zu $31 \% \%$. Man darf daher mit Recht annehmen, dass die Molekularbrechung des Chlorwasserstoffgases

1) L. Lorenz, Wiedem. Annal. 11, 70 (1880). chim. et d. phys. 31, 154 (1826).

2) Dulong, Annal. d. 
Ober d. Einfluss d. einfachen u. d. sogenannten mehrfachen Bindung etc. 343 von der Summe der Atomrefraktionen der Bestandteile nur in äusserst geringem, für chemische $Z$ wecke jedenfalls ganz zu vernachlässigendem Maasse abweicht.

Die Atomrofraktion des Wasserstoffs in den flüssigen organischen Verbindungen wurde im Mittel zu 1.04 bestimmt, während sich für das gasförmige Element durchschnittlich 1.05 ergab - also eine so gut wie vollständige Ubereinstimmung. Das Chlor in den flüssigen organischen Körpern besitzt eine mittlere Atomrefraktion von 6.02, während ihm im elementaren Zustande und als Gas der Wert 5.78 zukommt. Der Unterschied erreicht hier $4 \%$, ist also gleichfalls noch gering und überschreitet kaum die Abweichungen, welche sich unter den einzelnen, aus den verschiedenen Chlorverbinḍungen abgeleiteten Werten ergeben.

Die Atomrefraktion des Kohlenstoffs dagegen variiert, je nachdem er einfach oder doppelt gebunden ist, von 2.48 bis $2.48+\frac{1.78}{2}=3.37$, oder um $36 \%$. Noch grösser ist die Atomrefraktion des acetylenartig gebundenen Kohlenstoffs: $2 \cdot 48+\frac{2 \cdot 18}{2}=3.57$. Der Unterschied erreicht hier $44 \%$. Ïhnliche, wenn auch nicht so grosse Änderungen, finden boi dem Sauerstoff in seinen beiden Bindungsformen statt. Bei dem Ubergang der Gruppe $C-O$ in $C=O$ wächst der Refraktionswert durchschnittlich von $4.06(2.48+1.58)$ auf $4.82(2.48+2.34)$, also um $19 \%$.

Die Ansicht, nach welcher die monovalenten Grundstoffe konstante oder doch anuähernd konstante Atomrefraktion besitzen, wird also durch obige Beobachtungen vollkommen bestätigt. Gleicbzeitig ist hierdurch ein neues und wichtiges Argument für die Annahme erbracht, dass das verschiedene Lichtbrechungsvermögen polymerer und gewisser isomerer Körper in der Hauptsache von der verschiedenen Sättigung oder Bindungsweise des Kohlenstoffs und auch des Sauerstoffs herrührt. Das Refraktionsgesetz ist somit um eine wertvolle Stütze bereichert worden.

\section{$\S 10$.}

\section{Die Konstitution des Benzols und seiner Abkömmlinge.}

Die Frage nach der chemischen Struktur der Benzolverbindungen hat in jüngster Zeit eine ganz unerwartete Wendung genommen. Während man früher der Ansicht war, dass alle sogenannten aromatischen Körper sich von ein und demselben Modell durch einfache Substitution ableiten, weiss man jetzt, dass der Benzolkern gar nicht die Stabilität besitzt, die man ihm bisher zugeschrieben hatte. Das Benzol selbst kann natuirlich wie jedes andere chemische Individuum nur eine bestimmte Konstitution 
besitzen, es ist aber kein Zweifel mehr, dass in den Abkömmlingen mancherlei Verschiebungen in der Bindungsweise des sechsgliedrigen Kernes vorkommen. Teils treten schon bei der Entstehung dieser Körper durch natürliche oder künstliche Synthese die Kohlenstoffatome des Benzolgerüstes in ein Bindungsverhältnis, welches verschieden ist von dem im Benzol selbst stattfindenden, teils erleiden die fertig gebildeten Körper sehr leicht Atomumlagerungen, wodurch wiederum Änderungen in der Struktur des sechsgliedrigen Ringes erfolgen.

Während dem Benzol selbst auf Grund der gegenwärtigen chemischen Erfahrung nur eine der beiden bekannten Formeln
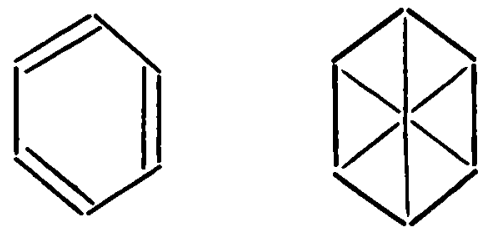

zugeschrieben werden kann, ist es hüchst wahrscheinlich, dass in gewissen Terpenen, den Pinenen nämlich, eine gemischte Form des Benzolkerns, mit Äthylen- und Parabindungen, vorliegt, von dem Typus

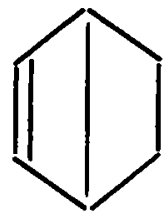

oder

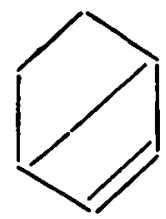

Die Pinene selbst sind ziemlich labile Verbindungen. Sie erleiden, wie man schon seit einer Reihe von Jahren weiss ${ }^{1}$ ), durch Temperaturerhöhung Isomerisation, indem sie in stabilere Gebilde, mit zwei $\ddot{A}$ thylenbindungen, übergehen, etwa von der Form

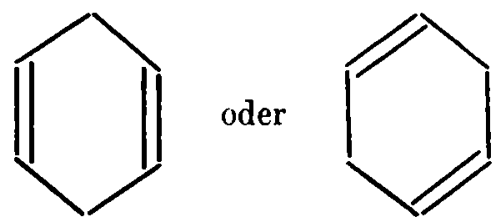

In dieselbe Modifikation, das Dipenten, verwandeln sich nach Wall ach ${ }^{2}$ ) auch andere, bereits zwei Äthylengruppen enthaltende Terpene, wie z. B. das von Heiur. Goldsch midt ${ }^{3}$ ) aufgeklärte Limonen

1) M. Berthelot, Annal. chim. phys., (3) 39, 16 (1853); J. Riban, loc. cit., (5) 6, 215 (1875). $\quad$ y) O. Wallach, Liebigs Annal. 227, 277 (1885).

3) H. Goldschmidt, Ber. Deutsch. Ghem. Gesell. 20, 491 (1887). 
Ober d. Einfluss d. einfachen u. d. sogenannten mehrfachen Bindung etc. 345

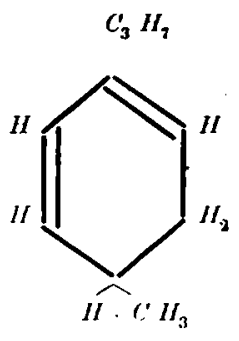

Als Ursache der Umwandlung in diesen Fällen kann man sich sehr wohl ein Bestreben zur Erzeugung symmetrischer Bildungen denken. Denn die Pinene und das Limonen von obigen Formeln sind asymmetrisch und sie drehen auch wie die meisten anderen Terpene die Polarisationsebene - während das nach vorstehender Formulierung symmetrische Dipenten (synon. Disopren, Kautschin etc.) inaktiv ist. ${ }^{1}$ )

Die Art von Isomerie, wie sie zwischen Pinen und Dipenten besteht - ein spezieller Fall der Sättigungsisomerie - könnte zweckmässig „,Paramerie" genamnt werden. Es ist möglich, ja ich glaube bereits Anhaltspunkte dafür zu besitzen, dass auch Paramerien von der Form
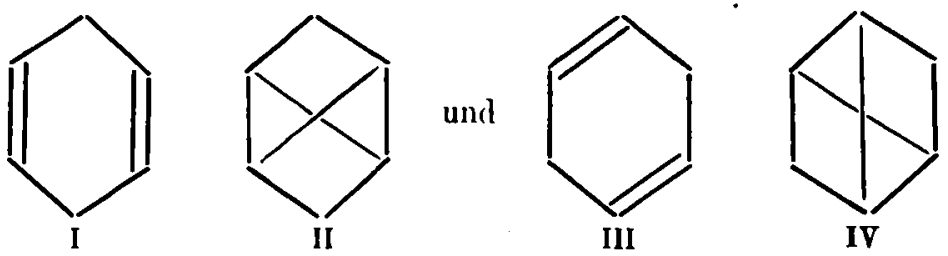

existicren. Fs kann möglicherweise das Schema II dem inaktiven, IV dagegen dem aktiven Camphen zukommen:

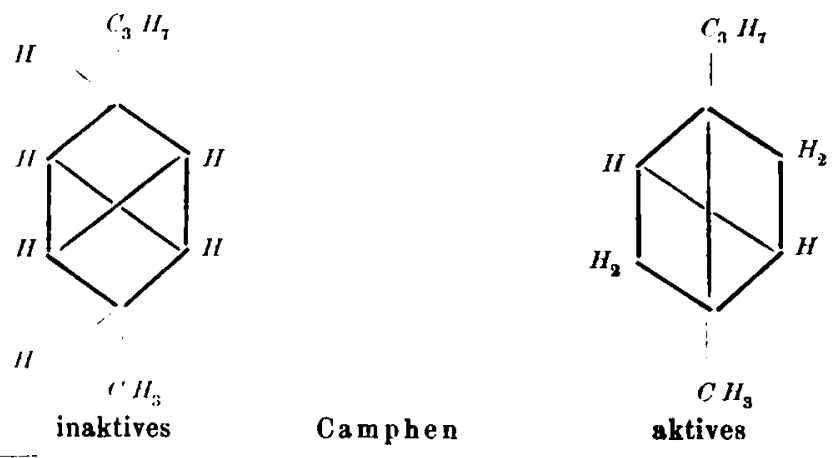

1) Unter symmetrisch resp. asymmetrisch bezeichne ich hier Kürze halber sowohl die allgemeine Gestalt der Molekel als auch die Abwesenheit bezw. Gegenwart Le-Bel-van't Hoffscher Kohlenstoffatome. Bei den Terpenen findet, wie es scheint, in der Regel Koinzidenz statt. 
Die Gründe, deren Entwicklung mich hier zu weit führen würde, sollen in einer demnächst folgenden Abhandlung angegeben werden.

Dem Typus II gehört möglichorweise auch das Chinon an, wenn es, wie heute wohl meistens angenommen wird, ein Diketon ist '), und ebenso das Chinondioxim ${ }^{2}$ )
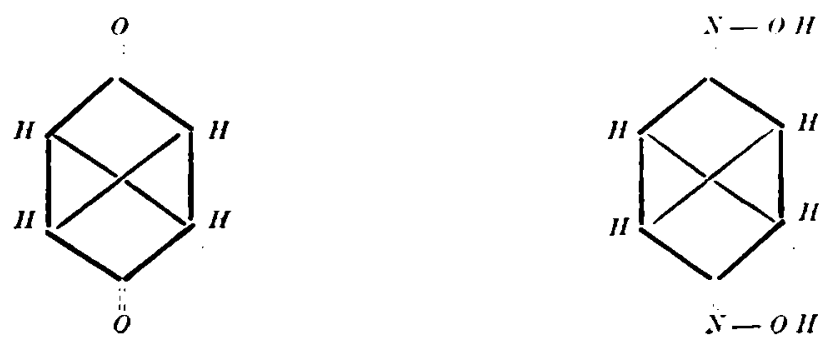

obwohl auch die „äthylenische“ Form
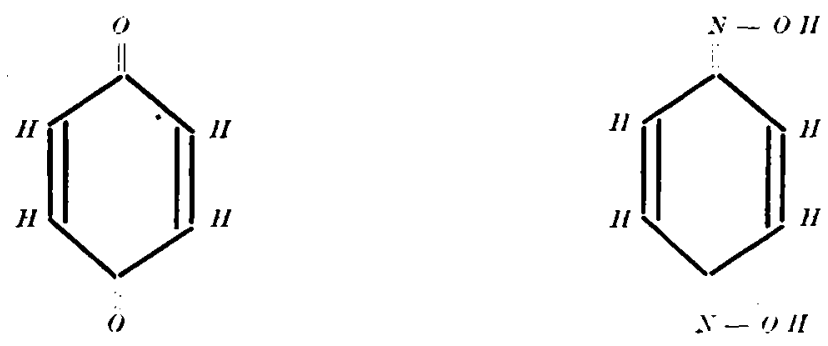

noch keineswegs ausgeschlossen ist.

Wie dem nun auch sei - die Bindungsverhältnisse der sechs Kohlenstoffatome sind in diesen Körpern jedenfalls nicht dieselben wie im Benzol. Sie werden aber dieselben, wenn dic genannten Körper in Hydrochinon oder Dinitrosobenzol umgewandelt werden:
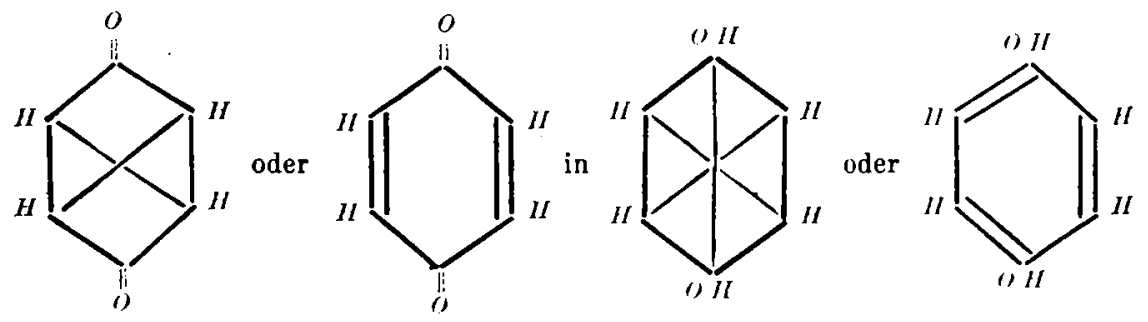

1) R. Nietzki u. Fr. Kehrmann, Ber. Deutsch. Chem. Gesell. 20,322 (1887). Dieselben, a. a. 0., S. 613. 
Ôber d. Einfluss d. einfachen u. d. sogenannten mehrfachen Bindung etc. 347
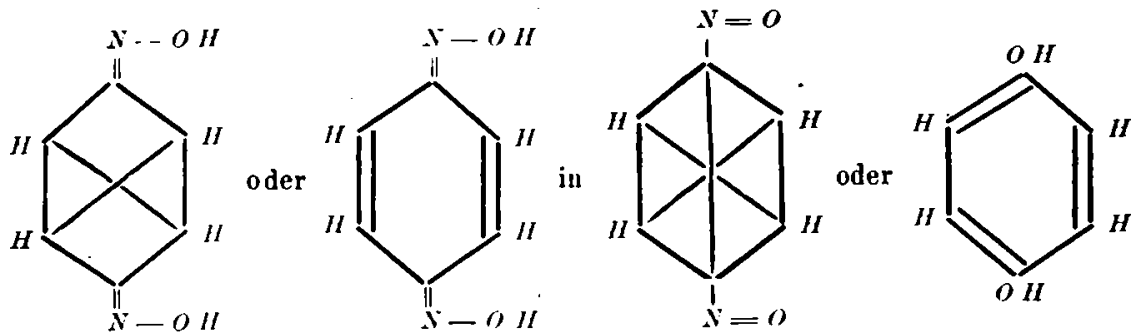

Diese Unwandlungen erinnern sehr an Ad. Baeyers ${ }^{1}$ ) klassischen Nachweis des Uberganges sogenaunter ,sekundärer" in „tertiäre" Formen, welche Transformation neuerdings auch am Carvol und Carvacrol ${ }^{2}$ ) und bei anderen Ketonen ${ }^{3}$ ) erkannt worden ist:

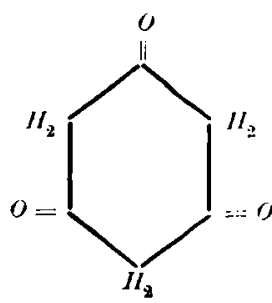

Sek. Phloroglucin

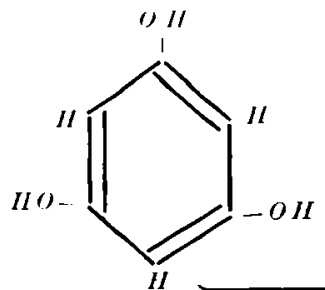

oder

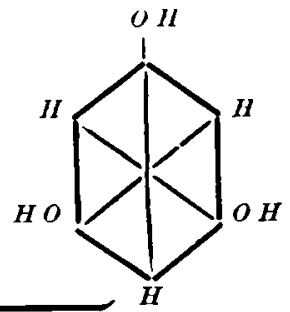

Tert. Phloroglucin
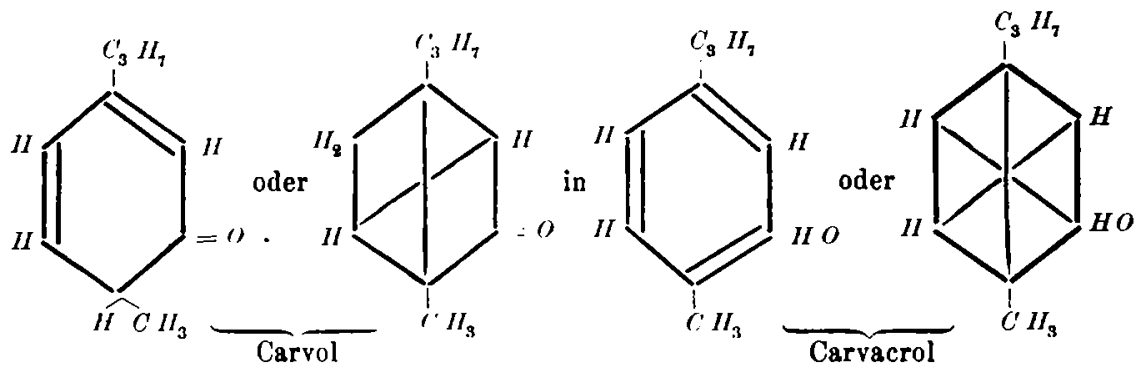

Diese, jetzt auch wohl „Tuntomerisation" genaunte Umwandlung der Bindungsverhältnisse des Kernes war es vorzüglich, welcho die Aufmerksamkeit auf die Wandlungsfähigkeit des Benzolringes lenkte.

Eine Frage nach der Konstitution der Benzolverbindungen, in der früheren allgemeinen Fassung, existiert also heute überhaupt nicht mehr. Sie hat eine ganz andere Gestalt gewonnen und es handelt sich nunmehr um die Lösung mehrerer Probleme - nachdem es sich gezeigt hat, dass die Verbindungen der aromatischen Reihe nicht nach einer einzigen

1) Ad. Baeyer, Ber. Deutsch. Chem. Gesell. 18, 3458 (1885), 19, 162 (1886). 2) Heinr. Goldscbmidt, a. a. O., 20, 490 (1887).

s) A. Hantsch u. seine Schúler, a. a. $0.20,1303$ fí. (1887). 
Schablone gebildet sind, sondern dass mehrere Leitformen vorkommen, denen sich die einzelnen Körper einreihen.

Die Aufgabe der heutigen Forschung ist es nun, die Konstitution mindestens eines der Hauptrepräsentanten jeder dieser typischen Gruppen festzustellen.

Nachdem man nun erkannt hat, dass die mehrfachen Bindungen der Atome die Molekularrefraktion der Körper um annähernd konstante Beträge erhöhen, während die einfachen Verkettungen - seien sie nun Parabindungen oder nicht - von keinem wesentlichen Einfluss sind, wird man sich der refraktometrischen Methode bedienen können, um zu entscheiden, welcher der Leitformen ein in Frage kommender Körper angehört. Und diese Methode wird gerade da von Nutzen sein, wo das chemisch-analytische oder synthetische Verfahren in derartigen prinzipiellen Fragen zu keiner endgültigen Entscheidung fübrte.

Was nun das Benzol selbst anbetrifft, so stehen ja nur noch zwei Konstitutionsformeln zur Diskussion: eine solche mit drei einfachen und drei doppelten, die andere mit neun einfachen Kohlenstoffbindungen. Im ersteren Fall müsste das Benzol ein Refraktionsinkrement von annähernd $3 \cdot 1,78$ besitzen, im anderen dagegen die aus der empirischen Zusammensetzung $C_{6} H_{6}$ folgende Molekularrefraktion $R=21 \cdot 12$. Aus der Tabelle 5 auf Seite $312-313$ ergiebt sich nun, dass die beobachtete Molekularbrechung 25.93 ist, woraus also ein Refraktionsinkrement von $3 \cdot 1,60$ folgt.

Es kann demnach kein Zweifel sein, dass drei $\ddot{A}$ thylengruppen im Benzol selbst enthalten sind, entsprechend der Formel Kekulés.

Ich kann indessen noch ein neues und hochwichtiges Argument beibringen, und dieses besteht in dem optischen Resultat der Polymerisation des Acetylengases zu flüssigem Benzol.

Die "brechende Kraft" $(n-1)$ des Acetylengases gegen Luft hat Mascart ${ }^{1}$ ) gemessen, und für Natriumlicht den Wert 2.075 crhalten, aus welchem sich der unten angegebene Brechungsindex $n_{D}$ ergiebt. Mit Hilfe der theoretischen Dichte lässt sich dann die spezifische und molekulare Refraktion des Acetylens bei $0^{\circ}$ und $760 \mathrm{~mm}$ Druck in Bezug auf den Strahl $D$ ableiten und mit dem gleichfalls für $D$ berechneten korrespondierenden Werte des flüssigen Benzols vergleichen. Man kann indessen auch für das Acetylen, wie vorher bei dem $̈$ thylen geschehen ist, die Konstanten in Bezug auf den Strahl C ermitteln. Zu diesen Zrecke bestimmt man die Dispersion des homologen Pentylacetylens oder Hepti-

J) Mascart, Compt. rend, 86, 1182 (1878). 
Ober d. Einfluss d. einfachen u. d. sogenannten mehrfachen Bindung etc. 349 dens, indem man spezifische und molekulare Brechung für die beobachteten Indices $n_{C}$ und $n_{D}$ berechnet. Die entsprechenden Grössen für die Linie $C$ beim Acetylen ergeben sich dann wieder durch einfache Proportionsrechnung. Der Brechungsindex $\boldsymbol{n}_{C}$ ist alsdann aus dem Refraktionsvermögen und der Dichte ebenfalls leicht abzuleiten, indem bei den Gasen mit hinreichender Genauigkeit $\frac{3}{2} \cdot \frac{n^{2}-1}{\left(n^{2}+2\right) d l}=\frac{n-1}{d}$ gesetzt und also mit Hilfe des bekannten $d$ auch $n$ berechnet werden kann. Auf diesem Wege sind die in nebenstehender Tabelle 16 mitgeteilten Konstanten für den Strahl $C$ beim Acetylen ermittelt worden und es kann nicht zweifelhaft sein, dass sie der Wahrheit sehr nahe kommen müssen. Ich füge auch die Daten für das Heptiden hinzu, welche bei diesen Rechnungen dienten. Die Beobachtungen sind von mir ausgeführt worden, ebenso auch die in der Tabelle bei Benzol angegebenen.

Gehen wir nun gleich zur Betrachtung der Molekularrefraktion über, indem wir zunächst beim Acetylen den beobachteten Wert in Bezug auf den Strahl $C$ mit dem theoretischen vergleichen. Die betreffenden Daten sind in der auf nächster Seite folgenden Tab. 17 zusammengestellt.

Man bemerkt, dass die beobachtete Molekularrefraktion des Acetylens den aus der empirischen chemischen Formel folgenden Wert $R$ sehr beträchtlich überschreitet. Die Differenz 2.02 ist als das Refraktionsinkrement der Acetylenbindung aufzufassen, wäbrend ich früher ${ }^{1}$ ) als Durchschnittswert dieser Bindung bei einer Reihe von Acetylenabkömmlingen $2 \cdot 18$ gefunden hatte.

Die Ubereinstimmung ist also eine sehr

1) J. W. Brühl, Liebigs Annal. $\mathbf{3 3 5 ,} 82$ (1886).

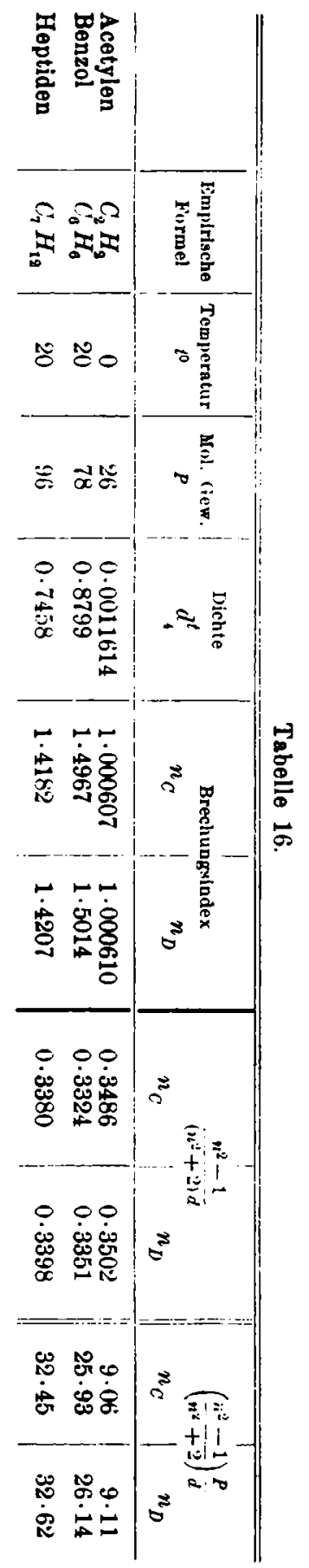


befriedigende: das Acetylengas schliesst sich in seinem optischem Verhalten den flüchtigen Abkömmlingen vollständig an.

Tabelle 17.

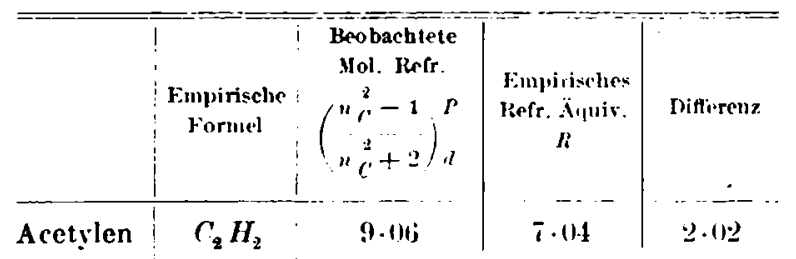

Wir haben nun vorher gesehen, dass bei Polymerisationsvorgängen, welche in vollständiger Aufhebung der mehrfachen Atombindungen und Umwandlung in einfache bestehen, auch das Refraktionsinkrement rollständig verschwindet. So verlieren drei Molekel Aldehyd bei Erzeugung von Paraldehyd ihren Brechungszuwachs 3.0,76, und fünf Molekel $\ddot{\Lambda}$ thylen beim Ubergang in Cymbydren oder Tetrahydroterpen ihr Inkrement $5 \cdot 1,61$.

Wenn daher das Benzol aus dem Acetylen in der Weise entsteht, dass drei dreifache oder $\Lambda$ cetylenbindungen in neun einfache ungewandelt werden:

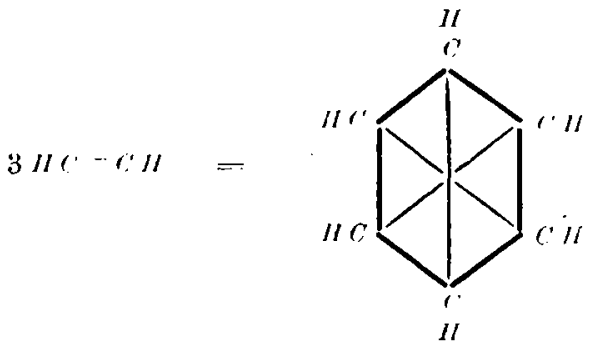

so ist zu erwarten, dass das Refraktionsinkrement dreier Acetylenmolekel, $3 \cdot 2,02=6 \cdot 06$, vollkommen oder nahezu verschwindet. Die Molekularrefraktion des flüssigen Benzols sollte dann also um circa 6.06 geringer sein als diejenige von drei Molekeln Acetylengas. Die Beobachtung ergiebt nun in Bezug auf die Strahlen $C$ und $D$ folgendes:

Truelle 18.

\begin{tabular}{|c|c|c|c|c|c|}
\hline & $\begin{array}{l}\text { Saturatiens- } \\
\text { frocuel }\end{array}$ & 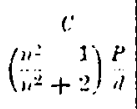 & Inifferenz & 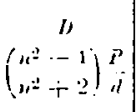 & I piftirenz \\
\hline $\begin{array}{l}3 \text { Mol. Acetylen } \\
=3\left(C_{z} H_{3}: \equiv\right) \\
=\text { Mol. Benzol }\end{array}$ & $\begin{array}{l}C_{0} H_{0} \equiv_{2} \\
C_{8} H_{b} 二_{0}\end{array}$ & $\begin{array}{l}27 \cdot 18 \\
25 \cdot 93\end{array}$ & $1 \cdot 25=3 \cdot 0,42$ & $\begin{array}{l}27 \cdot 33 \\
26 \cdot 14\end{array}$ & $1 \cdot 19=3 \cdot 0,40$ \\
\hline
\end{tabular}


Ober d. Einfluss d. einfachen a. d. sogenannten mehrfachen Bindung etc. 351

Die Polymerisation hat also keine Brechungsrerminderung von 6.06, sondern nur von 1.25 bezw. 1.19 zur Folge gehabt. Damit ist es erwiesen, dass die mehrfachen Kohlenstoffbindungen des Acetylens bei Umwandlung in Benzol keineswegs in lanter einfache umgewandelt worden sind. Das Benzol kann unmöglch neun einfache Kohlenstoffbindungen enthalten.

Das Refraktionsäquivalent der dreifachen Bindung im Acetylengas wurde nun, wie vorher erwähnt, zu 2.02 gefunden. Dasjenige der doppelten im Äthylengas ergab sich dagegen zu 1.61. Der Unterschied beträgt 0.41 . Das mittlere Inkrement der Acetylenbindung hatte sich aber nach früheren Beobachtungen an flüssigen Körpern zu 2.18 und das der Äthylenbindung bei gleichen Aggregatzustand zu 1.78 ergeben, was also einer durchschnittlichen Abnahme von 0.40 bei Umwandlung der Acetylen- in eine $\ddot{A}$ thylenbindung entspricht. Die Ubereinstimmung ist also eine vollkommene.

Nun erfolgt aber bei der Polymerisation dreier Acetylenmolekeln zu Benzol eine Refraktionsabnahme von $1 \cdot 25=3 \cdot 0,42$ bezw. $1 \cdot 19=3 \cdot 0,40$. Hier haben wir somit die schönste Beglaubigung der Thatsache, dass bei djesem Polymerisationsvorgange drei Acetylen- in drei Äthylenbindungen übergehen, wodurch die Refraktionsminderung von circa $1 \cdot 20=3 \cdot 0,40$ bewirkt wird. Es verwandeln sich also die Acetylenmolekeln bei dieser Polymerisation zunächst in folgender Weise:

$$
3 \mathrm{HC}=\mathrm{CH}=3-\mathrm{HC}=\mathrm{CH}-
$$

um alsdann zu dem Gebilde

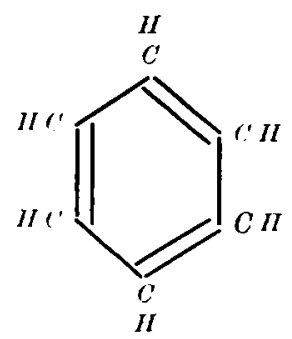

zusammerizutreten.

Für das Benzol selbst ist somit die Kekulé'sche Formel in $z$ uverlässigster Weise sicher gestellt.

Nach diesem Prototyp scheinen nun alle nicht hydrierten Benzolabkömmlinge, welche durch Ersetzung eines oder mehrerer Wasserstoffatome durch monovalente Grundstoffe oder Radikale entstehen, gebildet zu sein. Also auch die Homologen des Benzols und ihre Substitutionsderivate. Denn werfen wir den Blick rückwärts auf die Tabello 5, Seite 312-313, 
so finden wir, dass alle dort verzeichneten Benzolverbindungen, welche sämtlich dieser Kategorie zagehören, ein Refraktionsinkrement von durchschnittlich $3 \cdot 1,78$ besitzen. Die Ubereinstimmung ist eine um so vollkommenere, je weniger dispergent die betreffenden Substanzen sind.

Dass die hydrierten Benzolderivate nicht alle derselben Leitform angehören, geht schon aus dem hier bezüglich der Terpene Mitgeteilten hervor. Eine nähere Ausführung dieses Gegenstandes wird die Aufgabe einer nächsten Abhandlung bilden.

Welche Konstitution denjenigen Benzolverbindungen zukommt, die sich durch Ersatz der Wasserstoffatome des Benzols durch melrwertige Elemente oder Atomgruppen ableiten, bleibt noch zu erforschen. Diesbezügliche optische Beobachtungen liegen bisher nur ganz vereinzelt vor. Es wird mein Bestreben sein, diese Lücke durch Untersuchung der Chinone, Oxime und verwandter Körper auszufüllen. Indessen will ich hier vorläufig doch wenigstens ein Beispiel anführen.

Das Carrol ist nach den vorher erwähnten Untersuchungen Heinr. Goldschmidts ein Keton, welches sich in den Alkohol Carvacrol leicht umlagert und zu ihm in derselben Beziehung steht wie Baeyers sekundäres zum tertiären Phloroglucin. Dass Carvacrol ein Gebilde von der Ieitform des Benzols ist, muss nach dem vorher Erwähnten a priori wahrscheinlich genannt werden, denn die Substituenten im Carvacrol sind einwertige Reste. Es wird ihm also wahrscheinlich die Formel
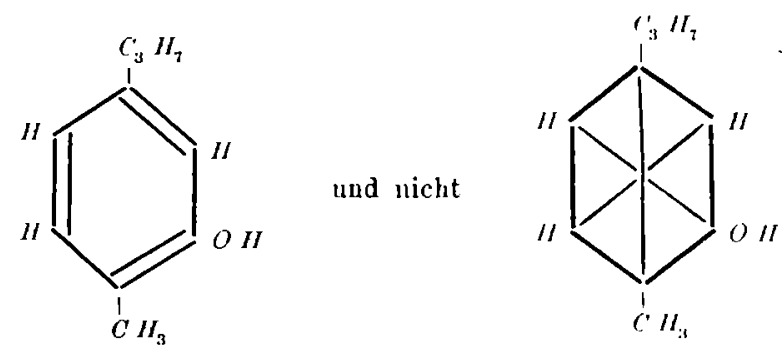

zukommen. Dagegen ist es vorläufig ungewiss, welche der Formen
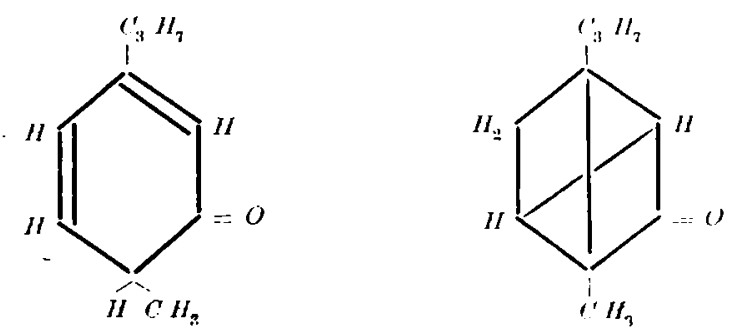

dem Carvol entspricht. 
Ober d. Finfluss d. einfachen u. d. sogenannten mehrfachen Bindung etc. 353

Die zur Beantwortung dieser Frage notwendigen Beobachtungen hat Hr. Gladstone beigebracht, und auch die Prüfung des eben bezüglich des Carvacrols gesagten ist durch die Messungen des Herrn Berliner ermöglicht. Diese Daten sind im folgenden von mir benutzt worden.

Tabelle 19.

\begin{tabular}{|c|c|c|c|c|c|c|c|c|}
\hline & $\begin{array}{c}\text { Enpirische } \\
\text { Formel }\end{array}$ & Tenper. & $\begin{array}{c}\text { Dichte } \\
d_{t}^{t}\end{array}$ & $\begin{array}{c}\text { Bre- } \\
\text { chungs- } \\
\text { Inder } \\
n_{C}\end{array}$ & $\frac{x^{2}-1}{\left(n^{2}+2\right) d}$ & $\left(\frac{n^{2}-1}{x^{2}+2}\right) \frac{p}{d}$ & $\begin{array}{c}\text { Empi- } \\
\text { riscbes } \\
\text { Refr. } \\
\text { Âquiv. } \\
R\end{array}$ & $\begin{array}{l}\text { Refractions- } \\
\text { Inkrement }\end{array}$ \\
\hline $\begin{array}{l}\text { Carvol } \\
\text { Carvacrol }\end{array}$ & $\begin{array}{l}C_{10} H_{14} O^{\prime \prime} \\
C_{10}^{\prime} H_{14} O^{\prime}\end{array}$ & $\begin{array}{l}11 \\
20\end{array}$ & $\begin{array}{l}0.9667 \\
0.9612\end{array}$ & $\begin{array}{l}1.4981 \\
1 \cdot 5000\end{array}$ & $\begin{array}{l}0 \cdot 3033 \\
0 \cdot 3060\end{array}$ & $\begin{array}{l}45 \cdot 49 \\
45 \cdot 90\end{array}$ & $\begin{array}{l}41 \cdot 70 \\
40.94\end{array}$ & $\begin{array}{l}79=2 \cdot 1,89 \\
96=3 \cdot 1,65\end{array}$ \\
\hline
\end{tabular}

Ein Blick auf die vorstehende Tabelle genügt, um sich davon zu überzeugen, dass in Bezug auf das Carvacrol die Erwartung vollkommen bestätigt wird. Die beobachtete Molekularbrechung dieses Körpers zeigt gegenüber dem aus der empirischen Formel abgeleiteten Refraktionsäquivalent $R$ einen Zuwachs, welcher den Wert $4.96=3 \cdot 1,65$, also sehr nahe denjenigen dreier $\mathrm{A}$ thylenbindungen $(3 \cdot 1,78)$, erreicht. Damit ist also festgestellt, dass Carvacrol nach dem Modell des Benzols gebildet ist keine Parabindungen enthält.

Die Beobachtung ergiebt nun aber weiter, dass auch dem Carvol noch zwei Äthylengruppen zukommen; das gefundene Refraktionsinkrement 2.1,89 zeigt dies mit grosser Schärfe. Das Carrol leitet sich demnach von demselben Stamm, demjenigen des Benzols, ab, und die paramere Form ist für dieses Keton ausgeschlossen.

Die analogen Beziehungen des sekundären und tertiären Phloroglucins dürften wohl den Schluss, dass auch dieser letztere Körper, $C_{6} H_{3}(O H)_{3}$, keine Parabindungen enthält, sondern ebenfalls der Leitform des Benzols nachgebildet ist, nicht als zu gewagt erscheinen lassen. Es stimmt dies übrigens auch mit Baeyers bekannten Resultaten überein.

Dagegen wäre es wohl voreilig, die Analogie auch auf die Paradiketone, die Chinone und ibre Abkömmlinge, ausdehnen zu wollen. Hier muss das Experiment erst die Entscheidung bringen. ${ }^{1}$ )

$\S 11$.

Die Konstitution des Naphtalins und seiner Derivate.

Wie bisher für das Benzol, so kommen auch für das Naphtalin zur Zeit nur noch zwei Konstitutionsformeln in Betracht. Als Gebilde von

1) Die Chinone, falls sie wirklich Ketone sind, durfte man den Terpenen an die Seite stellen. Wie diese als hydrierte Cymole, so konnten jene als hydrierte Benzolabkömmlinge, in welchen $H_{q}$ durch $O^{\prime \prime}$ vertreten ist, sufgefasst werden. Eine Wandlung der Bindungsverhāltnisse des Benzolgerdıstes bei der Hydrierung

Zeitschrift f, physik. Chemie. I. 
der Zusammensetzung $\left(C_{n} H_{z} n+2\right)-x H_{2}$ könnte die Naphtalinmolekel $n-1+x$, in diesem Falle also 16 einfache Kohlenstoff bindungen enthalten. Oder sie ist nach dem Modell des Benzols gestaltet, aus zwei äthylenischen Ringen zusammengesetzt, und es würden dann, der Erlenmeyerschen Konstitutionsformel entsprechend, 5 Äthylen- und 6 einfache Kohlenstoffverkettungen vorhanden sein. Im ersteren Falle sollte das Naphtalin das aus der empirischen Zusammensetzung folgende Refraktionsäquivalent $R$ besitzen, im anderen dagegen einen um das Inkrement von fünf Äthylenbiudungen, also um annähernd $5.1,78=8,90$ grösseren Wert. Dieser sehr beträchtliche Unterschied in der Molekularbrechung kaun demnach über die Zulässigkeit der einen oder anderen Strukturformel mit Sicherheit entscheiden.

Gladstone ${ }^{1}$ ) hat nun schon vor 17 Jahren das Refraktionsvermögen des Naphtalins in ätherischer Lösung untersucht und aus seinen Beobachtungen ergiebt sich bereits unzweifelhaft, dass diesem Körper eine bedeutend höhere Molekularrefraktion, als aus dessen empirischer chemischer Forinel folgt, zukomme. Dieses Resultat wird bestätigt durch die in neuerer Zeit von Nasini und Bernheimer ${ }^{2}$ ) ausgefuhrten Messungen am Naphtalin selbst in geschmolzenem Zustande, sowie an mehreren teils flüssigen, teils geschmolzenen Abkönmlingen desselben. Obwohl nun die beiden letztgenamuten Forscher die wahre Bedeutung ihrer Beobachtungen nicht erkannten und unhaltbare Schlüsse aus denselben zogen, so bleibt es nichtsdestoweniger ihr Verdienst, durch Herbeischaffung eines zuverlässigen experimentellen Materials unsere Lenntnisse der optischen Verhältnisse, insbesondere in der Gruppe der Naphtalinkörper, in erwünschtester Weise bereichert und so die Wissenschaft gefördert zu baben.

In der nachstehenden Tiblyelle 20 sind die hier in Betracht kommenden

(oder Ersetzung von $H_{2}$ durch $O^{\prime \prime}$ ) ist aber eine notwendige Konsequenz, so dass die Struktur des Kernes in den Chinonen wie in den Terpenen jedenfalls eine andere wäre als in dem Benzol selbst oder seinen einfachen Substitutionsprodukten. Welche der beiden I, eitformen

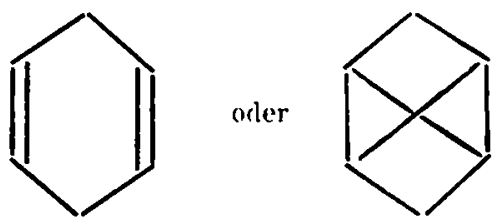

aber den Chinonen zukounen würde, muss, wie gesagt, erst durch das Experiment festgestellt werden.

J) J. H. Gladstone, Jouro. Chem. Soc., S, 147 (1870).

2) R. Nasini 1. O. Bernheimer, Accad. d. Jincei, Memoric (3), 18, (1884). 
Ober d. Einfluss d. einfachen a. d. sogenannten mehrfachen Bindung etc. 355

Beobachtungen vereinigt. Die Tabelle umfasst ausser den Kolumnen I bis XI noch einen aus drei nicht numericrten Spalten zusammengesetzten $\Lambda$ nhang, auf welchen wir weiter unten zurückkommen werden.

Die erste Horizontalabteilung enthïlt das Naphtalin selbst und solche Substitutionsprodukte desselben, welche durch Ersetzung eines oder mehrerer Wasserstoffatome durch monovalenteGrundstofie oder Reste entstanden sind. Die zweite $\Lambda$ bteilung bilden die hexalydrierten Naphtalinabkömmlinge und in der dritten sind endlich noch Beobachtungen für das mit Hexahydronaphtalin isomere Cymol zusammengestellt.

Betrachten wir nun zunächst die für das Naphtalin selbst und seine unmittelbaren Substitutionsderivate zusammengestellten Beobachtungen in der crsten Horizontalabteilung der Tabelle, so crgiebt ein Blick auf die Kolumne IX, dass alle diese Körper ein sehr bedeutendes Refraktionsinkrement aufweisen. Hieraus folgt mit Bestimmtheit, dass das zehngliedrige Kohlenstoffgerüst derselben nicht durch lauter cinfache Bindungen zu-

1) J. W. Brühl, Iiebigs Ann. 235, 1 (1886). ') J.H. Glad stone, Journ. Chem. Soc., 49, 623 (1886).
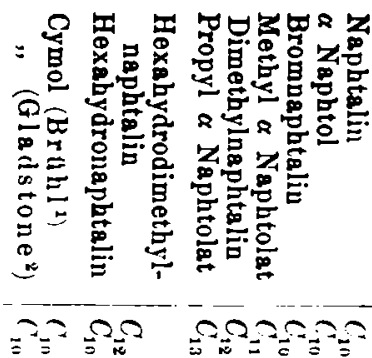

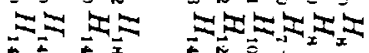
coto.

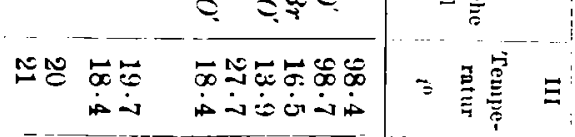
हक की समतन

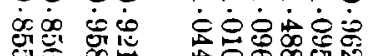

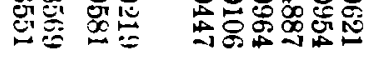

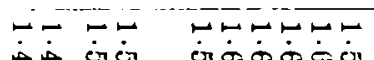

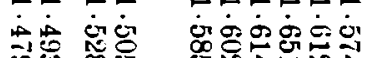

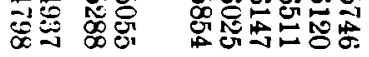
co \% \%की نे

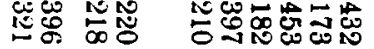

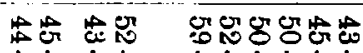

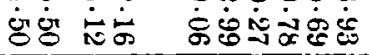

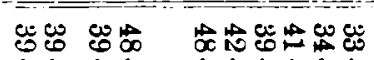

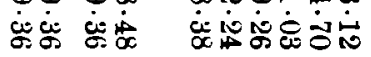

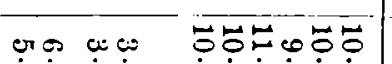

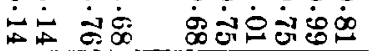
$\approx \stackrel{\Xi}{\stackrel{\Xi}{\Xi}}$

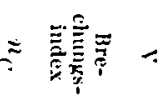
$\frac{n^{2}-1}{\left(n^{2}+2\right) d}=$ $\left(\overline{n^{2}+2}\right) d=$
$\left(\begin{array}{l}n^{2}-1 \\ n^{2}+2\end{array}\right)^{P}=$

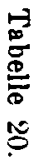

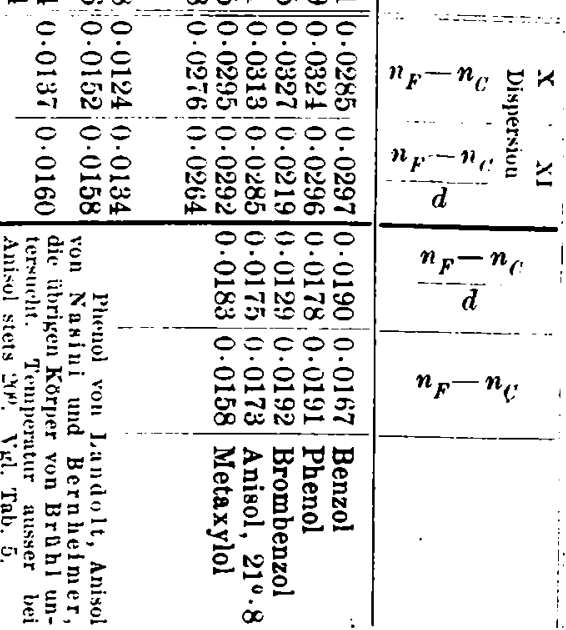


sammengehalten sein kann, sondern dass auch mehrere Äthylenbindungen vorhanden sein müssen, deren Anzahl durch die Inkrementskolumne z wischen füf und sechs angegeben wird. Denn es schwanken die Refraktionsüberschüsse in den einzelnen Fällen um circa $5 \cdot 1,78=8,90$ bis $6 \cdot 1,78=10,68$.

Die Erlenmeyersche Konstitutionsformel mit fünf Äthylenbindungen (welche neben einer solchen mit sechzehn einfachen allein in Betracht kommen konnte) hat sich also für das Naphtalin selbst und seine durchErsatz des Wasserstoffs durch monoralente Substituenten entstandenen Abkömmlinge in un$z$ weideutigster Weise als die richtige erwiesen.

Es ist für die Lösung der vorliegenden prinzipiellen Frage natürlich ganz irrelevant, dass die Refraktionsüberschüsse der verschiedenen Glieder der Naphtalinreihe nicht vollkommen genau unter einander und mit dem theoretischen Inkrement $\mathbf{5} \cdot \mathbf{1 , 7 8}=8,90$ übereinstimmen. Dies findet, wie wir vorher schon sahen, auch in keiner anderen Reihe, weder bei den Allyl-, den Benzol- orler irgend welchen anderen Verbindungen statt. Das Refraktionsinkrement der Äthylengruppe ist elyen kein absolut konstantes, und die Regel, nach welcher dic Brechungsuiberschüsse der ungesättigten Körper der in ihnen vorhandenen Auzahl von Äthylengruppen annähernd proportional sind, stellt wie das Dulong-Petitsche, das Gay Lussac-Mariottesche und viele anderen Naturgesetze, keinen streng genauen, sondern ebeu nur einen annähernden Ausdruck der Thatsachen dar. Derartige Gesetze sind Formeln für das Hauptsïchliche der Erscheinungen, während sie die unwesentlicheren Nebenumstände, welche die Erscheinungen gleichwohl, unter gewissen Bedingungen sogar recht merklich, modifizieren können, nicht in Betracht ziehen ${ }^{1}$ ). Wie das Gesetz von GayLussac-Mariotte nur in Bezug auf den idealen Gaszustand strenge richtig ist, so gilt dasjenige der Refraktionsproportionalität in seiner Strenge vielleicht für schr grosse oder unendliche Wellenlängen. Ich sage ,,vielleicht", weil der Einfluss abweichender Atomgruppierung in den verschiedenen Körperu möglicherweise immer einen gewissen, wenn auch meist geringen Einfluss ausüben wird. Die mit sichtbarem Licht erreichbaren Resultate werden aber in ganz zweifelloser und unter Umständen beträchtlicher Weise durch den Einfluss der verschiedenen Dispersion der Körper modifiziert. Dies ist erst vor kurzem von mir eingehend erörtert worden ${ }^{2}$ ) und ich beschränke mich hier auf einen ganz kurzen Hinweis.

In den Kolumnen X und XI der vorstebenden Tabelle 20 findet man

1) Man vergl. Herm. Kopp, Ber. Deutsch. Chem. Gesell. 16, 2458 (1883). ₹) J. W. Brūhl, Liebigs Annal. 235, 1: Ber. Deutsch. Chem. Gesell. 19, 2746 (1886). 
Ober d. Einfluss d. cinfachen u. d. sogenannten mehrfachen Bindung otc. 357 als „Dispersion“ die in der Differenz der Brechungsindices für die Strahlen $F$ und $C$ ( $\beta$ und $\alpha$ des Wasserstofflichts) gemessene Ausdehnung des Spektrums, $n_{F}-n_{C}$, und auch den auf gleiche Dichte reduzierten Wert, $\frac{n_{F}-n_{C}}{d}$, angegeben. Dieselben entsprechen vollkommen den früher von mir benutzten $B$ und $\frac{B}{d}$, in welchen $B$ den Cauch y schen Dispersionscoëfficienten darstellt. Denn da $B=\frac{n_{\mathrm{II}}-n_{\mathrm{I}}}{1}$, also die durch eine Konstante dividierte Differenz $\bar{\lambda}_{11}^{2}-\frac{1}{\lambda_{1}^{2}}$ der Brechungsindices darstellt, so müssen sich selbstverständlich dieselben Relationen ergeben, ob man nun $B$ oder $n_{11}-n_{1}$ benutzt. Es ist aber der letztere empirische Wert dem Cauchyschen vorzuziehen, da die vermeintliche theoretische Bedeutung desselben, wie ich entscheidend nachgewiesen habe ${ }^{1}$ ), gänzlich illusorisch ist. Alle übrigen Unvollkommenheiten des Coëfficienten $B$, die ich schon früher erwähnte ${ }^{2}$ ), haften freilich auch der Differenz der Brechungsindices an, und ebensowenig stellt der Wert $\frac{n_{\mathrm{II}}-n_{\mathrm{I}}}{\bar{d}}$ einen zur erschöpfenden Behandlung der Dispersion geeigneten Ausdruck dar, wie ich in einer besonderen Arbeit über diesen Gegenstand nachweisen werde. Für den vorliegenden Zweck: eine annähernde Schätzung der Dispersion können wir uns indessen der Differenz $n_{F}-n_{C}$ oder der im grossen und ganzen zu analogen Resultaten führenden, auf gleiche Dichte reduzierten, $\frac{n_{F}-n_{C}}{d}$ bedienen, in derselben Weise, wie früher zu dem gleichen $Z$ wecke der Coëfficient $B$ Cauchys oder $\frac{B}{d}$ von mir benutzt wurde.

Durchläuft man nun in der Tabelle 20 die Kolumnen $X$ und XI, so zeigt sich zunächst, dass in der That die Werte $n_{F}-n_{C}$ und $\frac{n_{F}-n_{C}}{d}$ im grossen und ganzen dieselben Ergebnisse liefern. Beide sind bei dem Naphtalin und seinen direkten Substitutionsabkömmlingen ungefähr doppelt so gross, als bei den hydrierten Naphtalinverbindungen oder dem Cymol.

In den drei letzten Spalten des Anhangs sind die den Naphtalinkörpern korrespondierenden Benzolverbindungen nebst den ihnen zukommenden Dispersionswerten zusammengestellt. Man sieht auch hier, dass in der Naphtalinreihe eine anderthalb Mal bis doppelt so grosse Dis-

1) J. W. Bráhl, Liebigs Annal. 236, 234 (1886). $\quad$ ") Derselbe, a. a. O., 235, 1 (1886). 
persion als bei den entsprechenden Gliedern der Benzolreihe stattfiudet. Bemerkenswert ist es, dass die auf gleiche Dichte gebrachte Dispersion, $\frac{n_{F}-n_{C}}{d}$, bei den beiden bromierten Produkten, dem Bromnaphtalin wie dem Brombenzol - deren Dichte auch die aller übrigen Körper sehr stark übertrifft - bei weitem geringer ist, als bei den andern Gliedern der Reihen. Wir sehen denn auch, dass das Refraktionsinkrement des Bromnaphtalins sich dem theoretischen $8,90=\check{\jmath} \cdot 1, \bar{\imath} 8$ erheblich mehr vähert, als das der übrigen, dispergenteren Naphtalinverbindungen. Es ist dies ein praktischer Fingerzeig, wie man es anzustellen hat, um die übermüssige Dispersion gewisser Körper herabzudrücken. Bei Gelegenheit einer speziell der Dispersion gewidmeten Arbeit werde ich auf diesen Gegenstand näher eingehen.

Es folgt aus dem Vorsteheuden unmittelbar, dass der Brechungsindex, daher auch die Molekularrefraktion und das Refraktionsinkrement, bei den Naphtalinverbindungen in viel stärkerem Maasse als in der Benzolreihe von der Dispersion beeinflusst und zwar erhöht werden muss. Die etwas zu grossen Inkremente bei dem Naphtalin und seinen Substitutionsderivaten finden in diesem Umstand eine genügende Erklärung, welche in dem Verhalten des Bromnaphtalins noch eine besondere Bestätigung findet. ${ }^{1}$ )

Von dieser modifizierenden Einwirkung hervorragender Dispersion sind nun die optischen Verhältnisse der hydrierten Naphtalinabkömmlinge, zu deren Betrachtung wir uns jetzt wenden, frei. Denn die Dispersion der genaunten Körper ist, wie ein Blick auf die Tabelle 20 lehrt, annähernd dieselbe wie die des Cymols und der meisten Benzolverbindungen. Es ist dies um so wertvoller, als man jene Naphtalinderivate mit isomeren Benzolkörpern vergleichen kann.

Das Hexahydronaphtalin, $C_{10} H_{14}$, ist isomer mit Cymol und das

1) Den von Hrn. Nasini (Accad. d. Lincei, Rendiconti, 3, 128, 164 [1887]) gegen diese Ansicht betreffs des Einflusses der Dispersion erhobenen Bedenken kann ich ein erhebliches Gewicht nicht beilegen. Es ist z. B. unwesentlich, wenn er zeigt, dass der Wert $\stackrel{n_{11}-n_{I}}{d}$ mit zunehmender Temperatur sehr schwach abnimmt, während das Refraktionsvermögen sehr schwach wächst. Dies beweist eben nur, dass eine Proportionalität der Grössen $\frac{n^{2}-1}{\left(n^{2}+2\right) d}$ und $\frac{n_{11}-n_{1}}{d^{2}}$ nicht vorhanden ist, was auch niemand behauptet hat. Worauf es aber hier hauptsächlich angekommen wäre, nämlich die Widerlegung der Ansicht, dass die Molektlarrefraktion isomerer und $z$ war stellungsisomerer Körper, die in der Regel sehr nahe gleich ist, aber sehr beträchtlich differiert, sobald ein bedeutender Unterschied in der Dispersion vorliegt, eben durch dieseu Einfluss der verschiedenen 
Über d. Einfluss d. einfachen u. d. sogenannten mehrfachen Bindung etc. 359

Hexahydrodimethylnaphtalin, $C_{1 y} H_{18}$, mit Triäthylbenzol. Die letzterwähnte Substanz ist bisher noch nicht optisch untersucht worden. Man kann aber mit einer der Sicherbeit nahe kommenden Wahrscheinlichkeit annehınen, dass die Molekularbrechung dieses Körpers, wie aller übrigen Homologen des Benzols, un ungefähr $3 \times 1.78$ den aus der impirischen Formel abzuleitenden Wert $R$ übertrifft. Es lässt sich demnach das molekulare wic das spezifische Brechungsvermögen des Triäthylbenzols (oder irgend eines Stellungsisomeren, wie z. B. Äthylbutylbenzol etc.) mit Annäherung berechnen und dic so erhaltenen Werte sind in die folgende Tabelle 21 eingefülırt.

Tabelle 21.

\begin{tabular}{|c|c|c|}
\hline & $\begin{array}{l}x^{2}-1 \\
\mid u^{2}+2 ! d l\end{array}$ & $\left(\begin{array}{c}n^{2}-1 \\
n^{2}+2\end{array}\right) d$ \\
\hline $\begin{array}{l}\text { IJexahydronaphtalin } \\
\text { Cymol (iladstone) } \\
, \quad(\text { Brühl) }\end{array}$ & $\begin{array}{l}0.3218 \\
0.3321 \\
0.3396\end{array}$ & $\begin{array}{l}43 \cdot 12 \\
44 \cdot 50 \\
45 \cdot 50\end{array}$ \\
\hline $\begin{array}{l}\text { Hexaluylrodimethylnaphtaliu } \\
\text { 'lriattbylbenzol (theoretisch) }\end{array}$ & $\begin{array}{l}0 \cdot 3220 \\
0 \cdot 332 \cdot 2\end{array}$ & $\begin{array}{l}52 \cdot 16 \\
53 \cdot 82\end{array}$ \\
\hline
\end{tabular}

In Bezug auf das Cymol stimmen die Beobachtungen nicht ganz befriedigend überein. Höchst wabrscheinlich ist das von Gladstone untersuchte Präparat das reinere gewesen, wie sich aus der vollkommeneren

Dispersion differiert - diese Widerlegung vermisse ich bei Hrn. Nasini. So ergab sich z. B.

\begin{tabular}{|c|c|c|c|c|c|}
\hline & & $\begin{array}{c}\left(\begin{array}{l}u^{2}-1 \\
n^{\boldsymbol{z}}+2\end{array}\right) \\
\text { Beobachtung }\end{array}$ & $\begin{array}{c}\text { H } \\
\text { Theorie }\end{array}$ & Differenz & $\frac{n_{F}-n_{c}}{d}$ \\
\hline $\begin{array}{l}\text { Allylphenolat } \\
\text { Zimmitalkohol }\end{array}$ & $l_{1} H_{10} I^{\prime}=$ & $\begin{array}{l}+1 \cdot 23 \\
42 \cdot 42\end{array}$ & $\begin{array}{l}41 \cdot 42 \\
41 \cdot 42\end{array}$ & $\begin{array}{l}\ldots 0.19 \\
+1.00\end{array}$ & $\begin{array}{l}0.0173 \\
0.0238\end{array}$ \\
\hline $\begin{array}{l}\text { Allylparakresolat } \\
\text { Anethol }\end{array}$ & $f\left(c_{30}, I_{12}()^{\prime}=\right.$ & $\begin{array}{l}45 \cdot 98 \\
47 \cdot 97\end{array}$ & $\begin{array}{l}45.98 \\
45.98\end{array}$ & $\begin{array}{r}0.00 \\
+1.99\end{array}$ & $\begin{array}{l}0.0180 \\
0.0257\end{array}$ \\
\hline
\end{tabular}

Die Dispersion des Allylphenolats und -parakresolats nähert sich derjenigen der Benzolverbindungen, welche wie jene beiden Körper normales Refraktionsinkrement besitzen, während Zimımtalkohul und Anethol sich in der Dispersion den Naphtalinkörpern năhern und auch wie diese eine gegen die Theorie etwas zu grosse Molekularrefraktion aufweisen. Der Einfluss der Dispersion ist hier wohl nicht zu bestreiten. Dass derselbe die einzige Ursache der vorkommenden Unregelmässigkeiten in den Refraktionsinkrementen sei, soll freilich eben so wie es früber nicht geschah auch gegenwărtig nicht behauptet werden. 
Ubereinstimmung der demselben zukommenden Molekularrefraktion mit dem theoretischen Werte 44.70 schliessen lässt.

Wären nun die hier angeführten Derivate des Naphtalins und des Benzols Gebilde, in denen nur einfache Kohlenstoff bindungen vorkommen, so würden im Hexahydronaphtalin und Cymol, zufolge ihrer gemeinsamen Formel $C_{10} H_{14}=\left(C_{n} H_{2} n+2\right)-4 H_{2}$ deren gleich viele, und zwar $n-1+4=13$ vorhanden sein. Hexahydrodimethylnaphtalin und Triäthylbenzol, beide von der Zusammensetzung $C_{12} H_{18}$, oder wieder $\left(C_{n}\right.$ $\left.H_{2 n+2}\right)-4 H_{2}$, würden dann 15 einfache Kollenstoff bindungen besitzen müssen. Es würde also bei den entsprechenden Isomeren eine gleiche Sättigung der Valenzen, mit anderen Worten, Stellungsisomerie vorliegen. Nun haben wir aber im vorhergehenden gesehen, dass das Refraktionsvermögen stellungsisomerer Körper von nicht zu sehr abweichender Dispersion stets nahezu identisch, dasjenige sättigungsisomerer dagegen verschieden ist. Aus der eben angeführten spezifischen und molekularen Brechung der hydrierten Naphtaline und ihrer Isomeren finden wir aber, dass eine Identität dieser Koustanten bei den betreffenden Isomeren nicht statt hat. Es geht daraus mit grösster Wahrscheinlichkeit hervor, dass die Verschiedenheit der entsprechenden gleich zusammengesetzten Körper auf einer Verschiedenheit in der Sättigung der Affinität und nicht nur in abweichender Konfiguration der Atome beruht. Die fraglichen Verbindungen können daher nicht Gebilde mit ausschliesslich einfacher Verkettung der Atome sein, da in solchem Falle eine andere als Stellungsisomerie gar nicht möglich wäre.

Sind dagegen Cymol und Triäthylbenzol nach der Leitform des Benzols gebildet und ist ferner Erlenmeyers Hypothese von der Gegenwart ron fünf Äthylengruppen im Naphtalinkern richtig, so werden die hexahydrierten Abkömmlinge desselben nur noch zwei Äthylengruppen enthalten können. Man hätte demnach die Zusammensetzung dieser Körper auszudrücken:

Cymol . . . . . . . . $C_{10} H_{14}={ }_{3}$
Hexahydronaphtalin . . . $C_{10} H_{14}={ }_{2}$
Triäthylbenzol . . . . . $C_{12} H_{18}={ }_{3}$
Hexahydrodimethylnaphtalin $C_{18} H_{18}={ }_{2}$.

Es ist nun vorher gezeigt worden, dass das spezifische Brechungsvermögen isomerer Körper sich um ungefähr eine Einheit der zweiten Decimale für dic Zusammensetzungsdifferenz von je einer Äthylenbindung unterscheidet. Die entsprechenden Werte in der Tabelle ergeben, dass dies auch hier stattfindet, und dass also in der That jene Benzolkörper eine Äthylenbindung mebr als die isomeren Hydronaphtaline enthalten. 
Ũber d. Einfluss d. einfachen n. d. sogenannten mebrfachen Bindung etc. 361

Dass aber in den Letzteren die absolute Anzahl der Äthylenbindungen $z w e i$, im Cymol dagegen drei beträgt, geht aus der Zusammenstellung der beobachteten Molekularrefiaktion und dem aus den empirischen chemischen Formeln sich ergebenden Werte $R$ hervor:

Tabelle 2\%.

\begin{tabular}{|c|c|c|c|c|}
\hline & & $\left(\begin{array}{l}n^{2}-1 \\
n^{2}+2\end{array}\right) p$ & $h$ & Differenz \\
\hline $\begin{array}{l}\text { Cymol } \\
\text { Hexahydronaphtalin } \\
\text { Hexabydrodimethylnapbtaliu }\end{array}$ & $\begin{array}{l}C_{14} H_{14}= \\
C_{10}^{\prime} H_{14}=2 \\
C_{12}^{\prime} H_{18}=2\end{array}$ & $\begin{array}{l}44 \cdot 50 \\
43 \cdot 12 \\
52 \cdot 16\end{array}$ & $\begin{array}{l}39 \cdot 36 \\
39 \cdot 36 \\
48 \cdot 48\end{array}$ & $\begin{array}{l}5 \cdot 14=3 \cdot 1,71 \\
3 \cdot 76=2 \cdot 1,88 \\
3 \cdot 68=2 \cdot 1,84\end{array}$ \\
\hline
\end{tabular}

Das optische Verhalten der hydrierten Naphtalinabkömmlinge, welches von dem Finfluss einer ausserordentlichen Dispersion frei ist, bestätigt also in ganz scharfer Weise die Frle nmeyer sche Naphtalinformel, während bei den nicht hydrierten und enorm dispergierenden Verbindungen dieser Klasse cine genauere Ubereinstimmung der beobachteten Refraktionsüberschüsse mit den theoretischen, als sie faktisch stattfindet, nicht erwartet werden kann. Durch diese gchäuften Thatsachen erscheint Erlenmeyers Strukturformel für das Naphtalin selbst, sowie fürdessen hier angeführte Abkömmlinge ebenso wohl begründet als Kekulés Annahme in Bezug auf die Konstitution des Benzols und die vorhin erwähnten Derivate desselben. ${ }^{1}$ )

Dass die spektrometrische Untersuchung die analoge Stammform für das Benzol und für das Naphtalin und ihre einfachen Abkömmlinge ergiebt, ist wohl ebenfalls als ein wertrolles Argument für die Richtigkeit der angenommenen Konstitutionsformeln dieser sich so nahe stehenden Körper aufzufassen. Und die allgemeine Ubereinstimmung der chemischen und der spektrometrischen Resultate, welche wir im Laufe dieser Untersuchungen kennen lernten, darf auch als ein erfreuliches Zeugnis für die praktische Brauchbarkeit der hier angewandten physikalischen Methode zur Erforschung der atomistischen Struktur der Körper begrüsst werden. ${ }^{2}$ )

1) Gewisse hydrierte Benzolabkōmmlinge (die Pinene und vielleicht auch die Camphene) enthalten, wie vorber erwähnt wurde, Parabindungen, in andercn aber (Dipenten, Limonen) sind solche nicht vorhanden, und zu der letzteren Art gehören also auch die hier angeführten bydrierten Naphtalinderivate.

9) Nachdem die vorliegende Arbeit bereits abgeschlossen war, ging mir die neueste Abhandlung des Hrn. Wallach (Liebigs Ann., 239, 1) zu, aus welcher sich ergiebt, dass der genannte Forscher betreffs der Konstitution einiger Terpene zu Ansichten gelangte, welche den hier vorgetragenen zum Teil sehr nahe kommen.

Freiburg im Breisgau, im Mai 1887. 